\title{
Retinal topography and microhabitat diversity in a group of dragon lizards
}

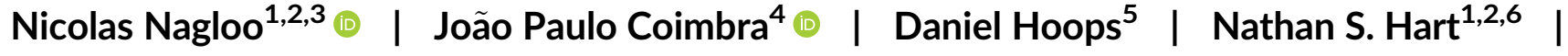 \\ Shaun P. Collin ${ }^{1,2,7}$ | Jan M. Hemmi ${ }^{1,2}$
}

${ }^{1}$ School of Biological Sciences, The University of Western Australia, Crawley, Western Australia, Australia

${ }^{2}$ The Oceans Institute and Oceans Graduate School, The University of Western Australia, Crawley, Western Australia, Australia

${ }^{3}$ Department of Evolutionary Studies of Biosystems, SOKENDAI (The Graduate University for Advanced Studies), Hayama, Japan

${ }^{4}$ School of Anatomical Sciences, The University of the Witwatersrand, Johannesburg, South Africa

${ }^{5}$ Ecology and Evolution, Research School of Biology, The Australian National University,

Canberra, Australian Capital Territory,

Australia

${ }^{6}$ Department of Biological Sciences, Macquarie University, Sydney, New South Wales,

Australia

${ }^{7}$ School of Life Science, La Trobe University, Bundoora, Victoria, Australia

\section{Correspondence}

Nicolas Nagloo, Laboratory of Neuroethology, Department of Evolutionary Studies of Biosystems, The Graduate University for Advanced studies, Kamiyamaguchi, Hayama 240-0193, Japan.

Email: nicolas.nagloo@gmail.com

Peer Review

The peer review history for this article is available at https://publons.com/publon/10. 1002/cne.24780.

\begin{abstract}
The well-studied phylogeny and ecology of dragon lizards and their range of visually mediated behaviors provide an opportunity to examine the factors that shape retinal organization. Dragon lizards consist of three evolutionarily stable groups based on their shelter type, including burrows, shrubs, and rocks. This allows us to test whether microhabitat changes are reflected in their retinal organization. We examined the retinae of three burrowing species (Ctenophorus pictus, C. gibba, and C. nuchalis), and three species that shelter in rock crevices (C. ornatus, $C$. decresii, and C. vadnappa). We used design-based stereology to sample both the photoreceptor array and neurons within the retinal ganglion cell layer to estimate areas specialized for acute vision. All species had two retinal specializations mediating enhanced spatial acuity: a fovea in the retinal center and a visual streak across the retinal equator. Furthermore, all species featured a dorsoventrally asymmetric photoreceptor distribution with higher photoreceptor densities in the ventral retina. This dorsoventral asymmetry may provide greater spatial summation of visual information in the dorsal visual field. Burrow-dwelling species had significantly larger eyes, higher total numbers of retinal cells, higher photoreceptor densities in the ventral retina, and higher spatial resolving power than rock-dwelling species. C. pictus, a secondary burrowdwelling species, was the only species that changed burrow usage over evolutionary time, and its retinal organization revealed features more similar to rock-dwelling species than other burrow-dwelling species. This suggests that phylogeny may play a substantial role in shaping retinal organization in Ctenophorus species compared to microhabitat occupation.
\end{abstract}

\section{KEYWORDS}

Ctenophorus, phylogeny, retinal asymmetry, retinal topography, RRID:SCR_001622, RRID: SCR_00195, RRID:SCR_002526, shelter type

\section{1 | INTRODUCTION}

The relatively high energetic cost of vision acts as a constraint on the development and growth of the visual system (Laughlin, 2001; Laughlin, van Steveninck, \& Anderson, 1998). Despite this energetic constraint, there is a strong selective pressure for visually oriented species to have well-developed visual systems to facilitate crucial tasks such as finding food and avoiding predators. This tension between constraints and functional pressures gives rise to a retinal organization where local areas of high neuron density provide 
enhanced visual performance in select regions of the visual field (Collin, 1999).

Among vertebrates and invertebrates alike, many studies demonstrate a strong correlation between the specialized distribution of retinal neurons and the visual landscape within the ecological niche of a species (Coimbra, Bertelsen, \& Manger, 2017; Coimbra, Collin, \& Hart, 2014; Coimbra et al., 2009, 2017; Hughes, 1977; Shand, Chin, Harman, Moore, \& Collin, 2000; Zeil \& Al-Mutairi, 1996; Zeil \& Hemmi, 2006). Usually found in animals that inhabit open and flat environments, horizontal visual streaks are elongated high-density retinal specializations that extend across the nasotemporal axis of the retina. They enhance panoramic visual sampling of the horizon, which potentially facilitates the detection of predators. In contrast to horizontal visual streaks, areas are concentric high-density specializations which afford enhanced visual sampling within a localized portion of the visual field. They are generally found in animals that inhabit cluttered environments and/or need enhanced visual guidance during foraging. Finally, foveas are high-density areas that feature a lateral displacement of higher order neurons, forming a pit in the retinal structure. The high density of neurons within the fovea mediates high-resolution vision, which is advantageous for the detection of fine details. In many animals, visual streaks, areas, and foveas can be combined to form diverse patterns of topographic distribution (Collin, 1999; Hughes, 1977). The topographic features of these patterns appear to be shared by closely related species suggesting a possible role of phylogeny in shaping the organization and density distribution of retinal neurons (Coimbra, Marceliano, Andrade-da-Costa, \& Yamada, 2006; Coimbra et al., 2009; Peichl, 2005; Reichenbach \& Robinson, 1995; Stone, 1983).

Among reptiles, lizards show a remarkable diversity of ecological lifestyles and a relatively well-understood phylogenetic history, which are important prerequisites to investigate the influences of phylogenetic and ecological constraints on retinal organization (Coimbra et al., 2009; Losos, 2011; Stone, 1983). Previous studies of retinal topography in some species of lizards have found the same three basic types of specializations (i.e., a horizontal streak, areas, and foveas), which are also found in other vertebrates (Barbour et al., 2002; Detwiler \& Laurens, 1920; Fite \& Lister, 1981; Röll, 2001a, 2001b; Underwood, 1951). Despite the efforts of previous studies to map the retinal topographic features of the lizard retina, information on the retinal organization of lizards is available for only a handful of distantly related species. This makes it difficult to understand how ecological and phylogenetic factors influence retinal organization in this group of reptiles. Thus, a detailed analysis of closely related species with contrasting visual ecologies will provide insights into the evolution of retinal specializations in lizards.

Dragon lizards (genus Ctenophorus) form a monophyletic group of 29 species endemic to semiarid and arid Australia (Greer, 1989). Despite sharing similar general body morphology and foraging ecology, dragon lizards differ in microhabitat use for shelter or refuge against predators. Some species shelter in burrows dug in sparsely vegetated sand ridges, where they also forage and bask on elevated wooden perches (Greer, 1989). In contrast, other species shelter among rocks on sparsely vegetated granite or sandstone rocky outcrops and use rocks to bask. The relatively open vegetation structure in both microhabitats leaves these lizards exposed in a flat environment where the early detection of predators (usually achieved visually) is crucial (Greer, 1989). Despite the diversity of these microhabitats, it remains poorly understood whether species of dragon lizards occurring in contrasting microhabitats have retinal specializations that reflect their visual ecology and habitat structure, or their ancestry.

To date, variations in neuronal density have been mapped for only two species of dragon lizards. However, these studies used different methods and provided contrasting results. A study using retinal wholemounts and retinal cross sections of the central-netted dragon (C. nuchalis) revealed a horizontal streak and a central area of high ganglion cell density, but no fovea (Wilhelm \& Straznicky, 1992). Another study using retinal cross sections of the ornate dragon (C. ornatus) showed a central fovea but no clearly defined horizontal streak (Barbour et al., 2002). The absence of a horizontal streak in the ornate dragon is intriguing since this species occurs in an open habitat where sampling of the horizon would be ecologically advantageous. Similarly, the lack of a fovea in the retina of the central-netted dragon is at odds with its visual needs for enhanced spatial resolution to detect small insects. While retinal cross sections used for the centralnetted dragon may facilitate counting of neurons in the fovea, previous studies indicate that this method is ill-suited to the reconstruction of retinal topography (Jamieson \& Fisher, 1971; Landau \& Dawson, 1970; Mass \& Supin, 1992, 2003, 2005; Nagy \& Ronald, 1970). Moreover, given its complex geometry, the fovea is prone to deformations depending on the method used to wholemount the retina, which may lead to its misidentification. Thus, it is unclear whether the differences in these previous studies reflect methodological issues or indicate natural variation of retinal features between these two species and their different microhabitats.

We used designed-based stereology and standard wholemount methods (Coimbra, Collin, \& Hart, 2015; Coimbra et al., 2006, 2009) to examine the retina of six species of the genus Ctenophorus (Figure 1) so that we could address these methodological issues and the lack of information on the topographic features of the retina of lizards. We mapped the density distribution of retinal neurons in the photoreceptor and retinal ganglion cell layer (RGCL) and discussed differences in retinal topographic features across evolutionarily stable ecological groups.

\section{MATERIALS AND METHODS}

\section{1 | Animals}

Samples used in this study are listed in Table 1. All individuals used were mature adults with an average weight $( \pm S D)$ of $12.7 \pm 3.3 \mathrm{~g}$. Animals were euthanized and perfused according to Hoops (2015) at the Australian National University (ANU) and the enucleated eyes subsequently shipped to The University of Western Australia (UWA). All procedures were approved either by the ethics committee of the ANU (A201149) and/or UWA (RA/3/100/1030). 

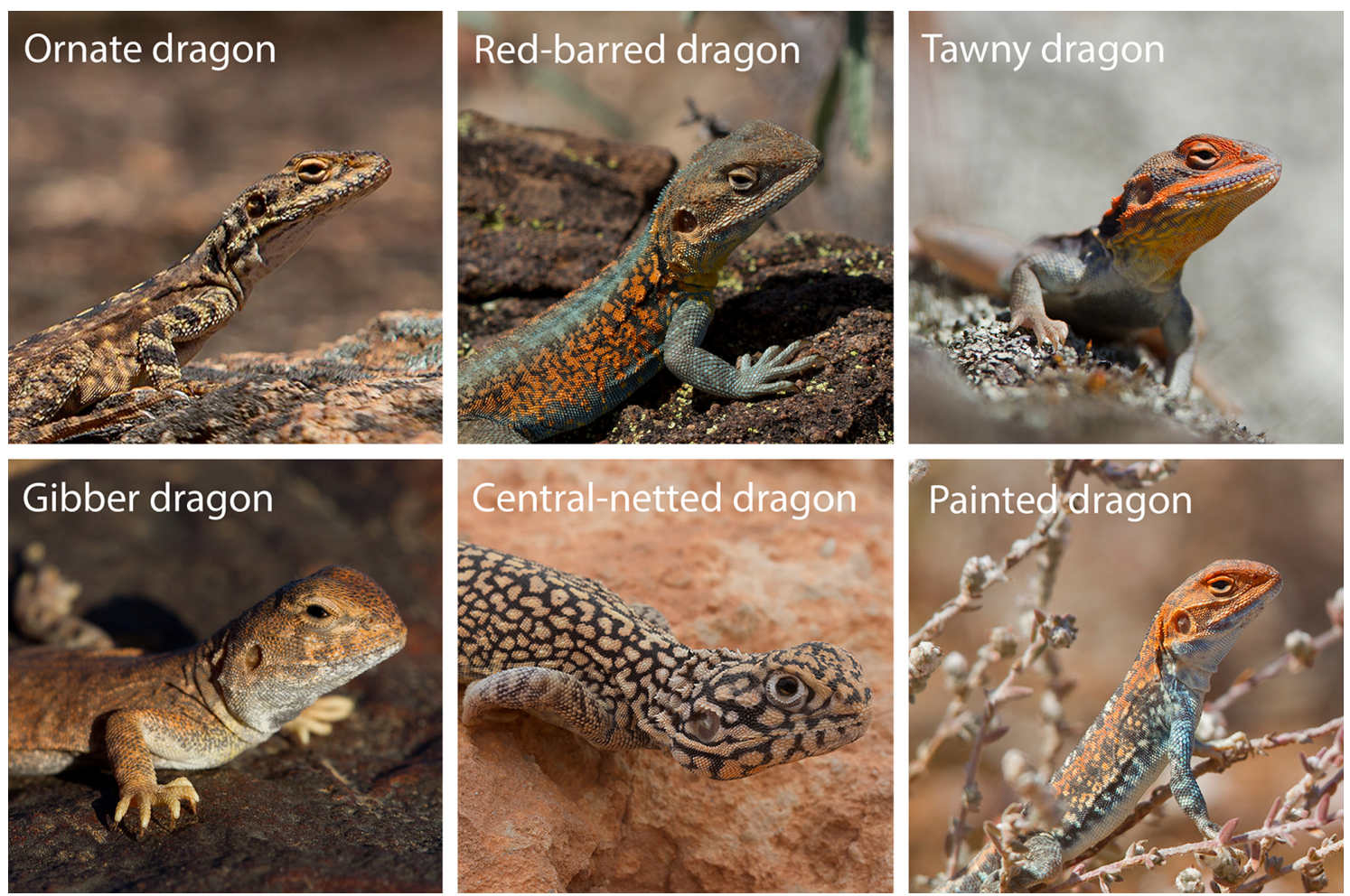

FIGURE 1 Profiles of the dragon lizard species examined. Left and center photographs provided by Angus Kennedy; right photographs provided by Tobias Hayashi [Color figure can be viewed at wileyonlinelibrary.com]

TAB LE 1 Number of individuals and retinae used to analyze the RGC and photoreceptor layer

\begin{tabular}{|c|c|c|c|c|}
\hline Species & Shelter type & Number of specimens & \multicolumn{2}{|c|}{ Number of retinal wholemounts } \\
\hline Gibber dragon (C. gibba) & Burrow & 5 (4 ơ; 1ㅇ) & 3 & 2 \\
\hline Central netted dragon (C. nuchalis) & Burrow & 3 (3 đ; 0 \&) & 2 & 2 \\
\hline Painted dragon (C. pictus) & Burrow & 4 (3 o; 1 ᄋ) & 3 & 2 \\
\hline Ornate dragon (C. ornatus) & Rock & 2 (unknown sex) & 1 & 1 \\
\hline Red-barred dragon (C. vadnappa) & Rock & 4 (3 ơ; 19) & 3 & 1 \\
\hline Total & & 23 & 15 & 10 \\
\hline
\end{tabular}

Abbreviation: RGC, retinal ganglion cell.

\section{2 | Dissection and preparation of retinal wholemounts}

Once each specimen was euthanized, the peripheries of the dorsal and nasal regions of its eyes were marked by the brief application of a cauterizer to the cornea (Coimbra, Hart, Collin, \& Manger, 2013). Whole eyes were then removed from the orbits and fixed by immersion in $4 \%$ paraformaldehyde in $0.1 \mathrm{M}$ phosphate buffer (PB) $(\mathrm{pH} 7.2)$ for $24 \mathrm{hr}$. After fixation, the eyes were stored in $0.1 \mathrm{M} \mathrm{PB}$ with $0.01 \%$ azide. The axial length of each fixed eye was measured using a digital caliper. The corneas were then removed with a continuous lateral incision at the limbus until it could be lifted off. A small incision was made on each dorsal ora for later orientation. The lens and excess vitreous were removed. The retinae were then isolated from the sclera and choroid by making a series of radial cuts that alleviated the tension across the hemisphere of the eyecup. The retinal pigment was then gently removed from the retina using fine-bristle paintbrushes and forceps where necessary. This revealed a diffuse yellow pigment spanning the nasotemporal axis at the retinal equator of all species in our study. This is similar to the diffuse yellow pigment previously reported by Barbour et al. (2002) in the ornate dragon lizard. The retinae were then bleached with $3 \%$ hydrogen peroxide in $0.1 \mathrm{M} \mathrm{PB}$ overnight and rinsed in 0.1 M PB before being further processed (Coimbra et al., 2009). 


\section{3 | Retinal wholemounts in glycerol}

Retinae used for the analysis of the density of photoreceptors were mounted with the photoreceptor layer facing up onto a nongelatinized glass slide in $80 \%$ glycerol in $0.1 \mathrm{M} \mathrm{PB}$ with $0.1 \%$ azide. To maintain a vertical orientation of the photoreceptor outer segments and reduce distortions in the wholemount, a frame of thin strips of filter paper was used between the slide and coverslip (Coimbra et al., 2015). Nail varnish was used to seal the preparation to prevent dehydration and stabilize the retinal wholemount. The low refractive index of the glycerol allowed easy visualization of the photoreceptor array, negating the need for staining prior to sampling. Apart from geckoes, lizards possess morphologically pure cone retinae (Walls, 1942). However, rod opsin (RH1) is expressed in a ratio of 1:16 of rod to cone opsin in the outer segment of cone photoreceptors in $C$. decresii (Yewers et al., 2015). Snakes possess similar cones expressing rod opsin and these possess the functional characteristics of cones (Schott et al., 2016). Here, we assume a similar cone-like functionality of rod opsin expressing cones enabling the counting of the total photoreceptor population including single and double cones. Double cones were easily identified by their large outer segments and were counted as a single functional unit (Figure 2a). Yellow pigmentation was also found in the photoreceptor inner segments (Figure $2 b$ ) across the equator of the retina similar to that found in the ornate dragon lizard retina (Barbour et al., 2002).

\subsection{Nissl staining of the RGCL}

Retinae used for the analysis of the RGCL were mounted on gelatinized slides and allowed to dehydrate overnight at room temperature in a chamber filled with formaldehyde vapors. This process increases adhesion of the retina to the gelatinized slide and improves cell differentiation during staining (Stone, 1981). Retinae were then rehydrated through an alcohol series of descending concentrations and stained in $0.1 \%$ aqueous cresyl violet solution for 5 min before being dehydrated again through an alcohol series, cleared in xylene, mounted in Entellan New (Merck, Darmstadt, Germany) and cover slipped (Coimbra et al., 2006). Shrinkage and warping due to dehydration of tissue during staining were minimal and limited to the edges of the wholemount because the tissue remained attached to the slide during all steps (Peichl, 1992; Wässle, Peichl, \& Boycott, 1981). Cell staining in the RGCL was relatively uniform except for glial cells, which were more darkly stained. Glial cells were also differentiated on the basis of their small size and irregular soma shape (Figure 2c,d). Since small ganglion cells and amacrine cells show similar cytological appearance in the ganglion cell layer, our counting included both the populations of amacrine and retinal ganglion cells to estimate the number and density of retinal ganglion cell layer neurons (RGCLn) (Figure $2 c, d)$. There was no significant difference (Ime, $d f=1, p>.05$, Model a in Table S1) in the retinal area of hydrated (for photoreceptor analyses) and dehydrated
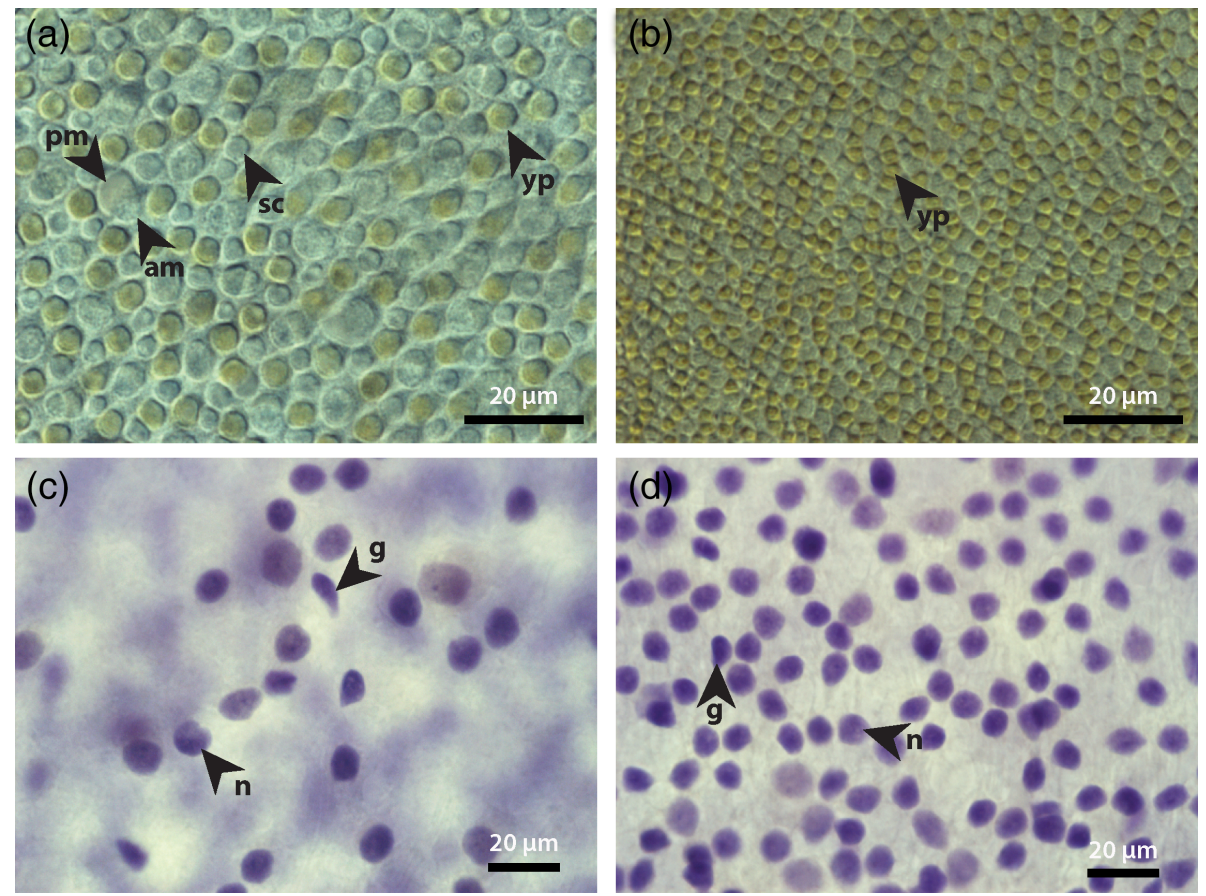

FIGURE 2 Cytological criteria used to identify cell types in the photoreceptor layer and the RGC layer. (a) Photoreceptors at medium density in the retina of $C$. pictus. (b) Photoreceptors at high density in the fovea of $C$. pictus. (c) RGCLn stained with Cresyl violet in the peripheral retina of $C$. decresii. (d) RGCLn in the dorsal retina of $C$. decresii. am, accessory member of a double cone; g, glial cells; $n$, neurons including RGCs and displaced amacrine cells; pm, principal member of a double cone; RGC, retinal ganglion cell; RGCLn, retinal ganglion cell layer neurons; sc, single cones; yp, yellow pigment in the inner segment of cones in the streak and central retina only [Color figure can be viewed at wileyonlinelibrary.com] 
(for RGCLn analyses) retinae. This suggests that the effects of dehydration and any consequent shrinkage were kept at a minimum in our preparations.

\section{5 | Designed-based stereology}

A $\times 4$ (NA 0.17) objective lens, Stereolnvestigator software (MBF Bioscience, Williston, Vermont), and a motorized stage (MAC200; Ludl Electronics Products, Hawthorne, New York) were used to visualize retinae and digitize the outline of retinal wholemounts. The optical fractionator method (West, Slomianka, \& Gundersen, 1991) modified by Coimbra et al. (2009) for its use in retinal wholemounts was used to sample the RGC and photoreceptor layers. Due to a foveal pit being present in all retinae, sampling regimes of increasing resolution were used to accurately sample the rapidly changing cell densities in this region (Coimbra et al., 2014, 2015). Four sampling protocols for four regions were used for the photoreceptor layer (Table 2) (Coimbra et al., 2014, 2015). These regions included the peripheral retina (periphery), the peripheral area surrounding the fovea (perifovea), the proximal regions to the foveal pit (parafovea), and the foveal pit (foveola) (Table 2). In contrast, three sampling protocols over three sampling regions of the RGCL were used as listed in Table 3. These three regions included the peripheral retina (periphery), the area surrounding the fovea (perifovea), and the area within the foveal pit (foveola) (Table 3). The coefficient of error (CE) is a measure of the precision of the population size estimates by the optical fractionator

TAB LE 2 Sampling protocol for assessing the density of photoreceptors in different retinal regions as shown in a representative specimen for each species

\begin{tabular}{|c|c|c|c|c|c|c|c|}
\hline $\begin{array}{l}\text { Shelter } \\
\text { type }\end{array}$ & Species & $\begin{array}{l}\text { Retinal } \\
\text { region }\end{array}$ & $\begin{array}{l}\text { Retinal } \\
\text { area }\left(\mathrm{mm}^{2}\right)\end{array}$ & $\begin{array}{l}\text { Counting } \\
\text { grid }(\mu \mathrm{m})\end{array}$ & $\begin{array}{l}\text { Counting } \\
\text { frame }(\mu \mathrm{m})\end{array}$ & $\begin{array}{l}\text { Number of sites } \\
\text { sampled }\end{array}$ & CE \\
\hline \multirow[t]{9}{*}{ Burrows } & \multirow{3}{*}{$\begin{array}{l}\text { Gibber dragon } \\
\text { (C. gibba) }\end{array}$} & Periphery & 62 & $500 \times 500$ & $20 \times 20$ & 244 & 0.05 \\
\hline & & Parafovea & 0.37 & $100 \times 100$ & $15 \times 15$ & 38 & 0.08 \\
\hline & & Foveola & 0.03 & $50 \times 50$ & $15 \times 15$ & 18 & 0.14 \\
\hline & \multirow{4}{*}{$\begin{array}{l}\text { Central-netted dragon } \\
\text { (C. nuchalis) }\end{array}$} & Perifovea & 2.3 & $250 \times 250$ & $20 \times 20$ & 31 & 0.09 \\
\hline & & Parafovea & 0.22 & $100 \times 100$ & $15 \times 15$ & 21 & 0.07 \\
\hline & & Foveola & 0.04 & $50 \times 50$ & $15 \times 15$ & 20 & 0.09 \\
\hline & & Total area & 80.56 & & Total sites & 282 & \\
\hline & \multirow{2}{*}{$\begin{array}{l}\text { Painted dragon } \\
\text { (C. pictus) }\end{array}$} & Foveola & 0.03 & $50 \times 50$ & $15 \times 15$ & 15 & 0.17 \\
\hline & & Total area & 52.32 & & Total sites & 323 & \\
\hline \multirow[t]{10}{*}{ Rocks } & \multirow{5}{*}{$\begin{array}{l}\text { Ornate dragon } \\
\text { (C. ornatus) }\end{array}$} & Periphery & 57 & $500 \times 500$ & $20 \times 20$ & 221 & 0.05 \\
\hline & & Fovea & 2.6 & $300 \times 300$ & $20 \times 20$ & 25 & 0.09 \\
\hline & & Parafovea & 0.38 & $150 \times 150$ & $15 \times 15$ & 16 & 0.09 \\
\hline & & Foveola & 0.02 & $40 \times 40$ & $15 \times 15$ & 15 & 0.13 \\
\hline & & Total area & 60.00 & & Total sites & 277 & \\
\hline & \multirow{2}{*}{$\begin{array}{l}\text { Tawny dragon } \\
\text { (C. decresii) }\end{array}$} & Periphery & 58 & $500 \times 500$ & $20 \times 20$ & 225 & 0.04 \\
\hline & & Perifovea & 1.5 & $200 \times 200$ & $20 \times 20$ & 34 & 0.04 \\
\hline & \multirow{3}{*}{$\begin{array}{l}\text { Red-barred dragon } \\
\text { (C. vadnappa) }\end{array}$} & Parafovea & 0.32 & $100 \times 100$ & $15 \times 15$ & 31 & 0.07 \\
\hline & & Foveola & 0.04 & $50 \times 50$ & $15 \times 15$ & 18 & 0.08 \\
\hline & & Total area & 50.66 & & Total sites & 326 & \\
\hline
\end{tabular}

Note: Schaeffer's CE associated with each sampling protocol (Glaser \& Wilson, 1998; Slomianka \& West, 2005).

Abbreviation: CE, coefficient of error. 
TAB LE 3 Sampling protocol for assessing the density of neurons in different regions of the retinal ganglion cell layer as shown in a representative specimen for each species

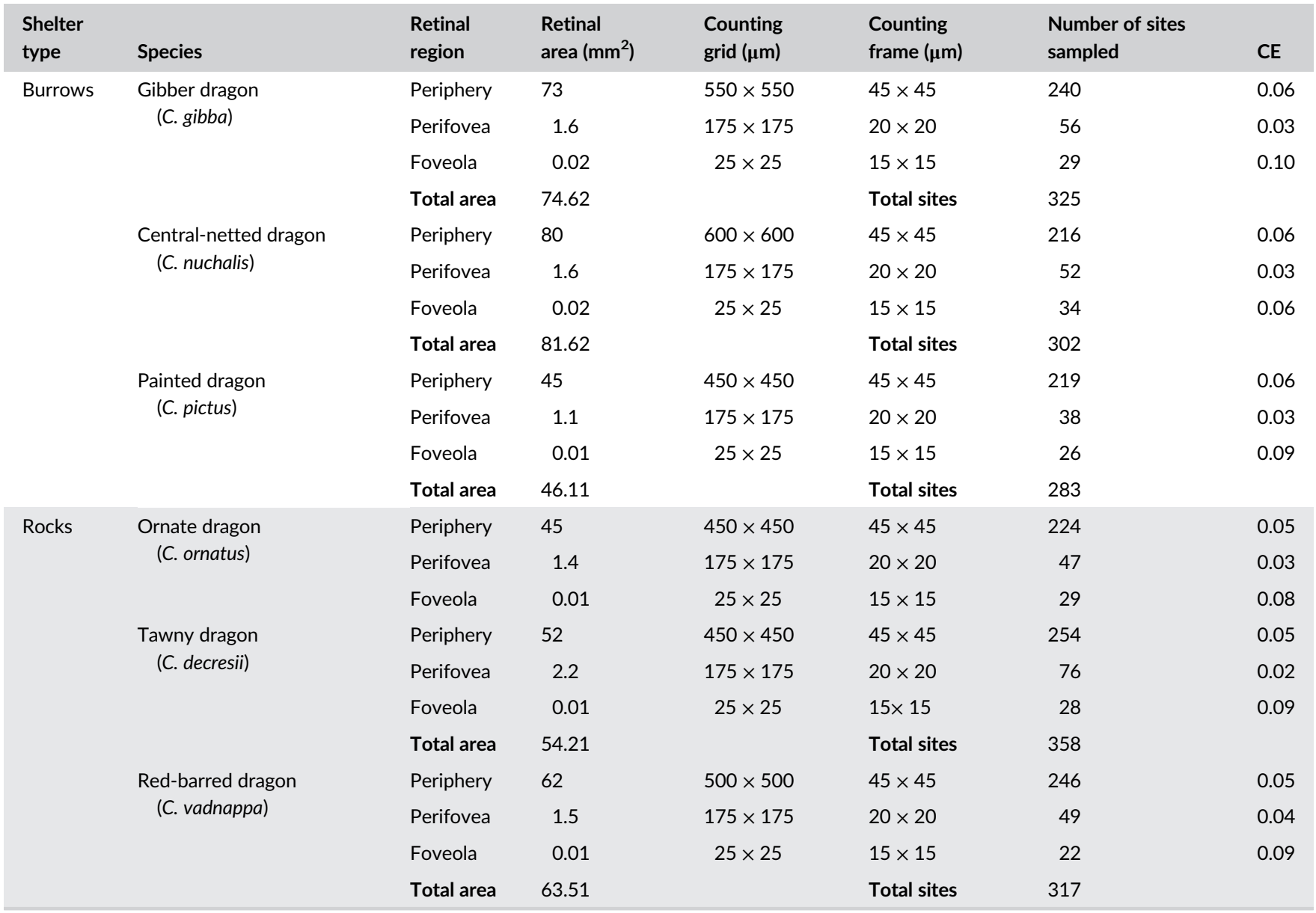

Note: Schaeffer's CE associated with each sampling protocol (Glaser \& Wilson, 1998; Slomianka \& West, 2005).

Abbreviation: $\mathrm{CE}$, coefficient of error.

method. There are several CE estimates, including the Gundersen \& Jensen $C E$, the nugget corrected Gundersen \& Jensen $C E$, and the Schaeffer CE. Among these, the Schaeffer CE is the most precise with the least variation across independent cell populations. Past simulations have revealed that over 1,000 independently simulated cell populations, the relationship between the $\mathrm{CE}$ and the number of cells counted per sampling location is such that if 100 cells are counted at a single location, the CE estimate approaches levels explainable by true variations within a cell population at a value of 0.1 . In our study, we aim for a Schaeffer CE of 0.1 or less in most sampling protocols. However, in areas where steep gradients in cell density are present (e.g., area around the foveal pit in the photoreceptor layer), slightly higher CEs are expected due to the rapid changes in cell density. Smaller counting frames are adopted in areas of rapid density changes to minimize this effect until the CEs are within an acceptable range (Glaser \& Wilson, 1998; Slomianka \& West, 2005).

Within each square of a randomly placed, regular sampling grid, a sampling frame of predefined size was used to sample the retina and to represent the area covered by the square. Only neurons within the sampling frame that did not touch the exclusion borders were marked (Gundersen, 1977). The total number of markers that are both within the sampling frame and the outline of the retinal region were used to estimate the density and the total number of neurons in each grid area. Neuron counts at all grid locations were summed to estimate their total number according to the algorithm below:

$$
N=\Sigma Q * 1 / \text { asf }
$$

where asf is the area sampling fraction and $\Sigma Q$ is the number of markers counted within a frame, and $N$ is the total number of cells estimated within the area represented by the grid (Coimbra et al., 2009).

\section{6 | Average regional cell densities}

Cell density in the photoreceptor layer and the RGC layer was averaged over $20 \mu \mathrm{m}$ intervals from the foveal center to the retinal periphery in the dorsal, ventral, nasal, and temporal regions. To enable consistent comparisons of cell densities for both populations of neurons, retinal regions were examined at two eccentricities: central ( $<1 \mathrm{~mm}$ from the foveal center) and peripheral ( $>1 \mathrm{~mm}$ and $\leq 3.5 \mathrm{~mm}$ from the foveal center). 


\section{7 | Statistical analysis}

All statistical analyses were conducted using R software (R Core Team, 2016). Linear mixed effects models in the Ime4 package (Bates, Maechler, Bolker, \& Walker, 2015) were used to compare cell densities across regions and shelter type with "individual" included as a random effect to account for repeated measures. Stepwise factor selection was used to build final linear models which only contained factors significant at the $5 \%$ level. All $p$ values presented were tested against the final models. Normality of final residuals was checked using a combination of qqplots and Shapiro-Wilk tests. Analysis of response variables where there were no repeated measures (axial length of the eye, retinal area, total number of neurons, peak neuron density, and spatial resolving power [SRP]) was carried out using the base $1 m$ function for linear models in R. Effect size of shelter type on response variables was standardized and expressed as a proportion of pooled SD (Cohen, 1988). For comparison across shelter types, we conducted analyses with C. pictus as a burrower, and with C. pictus grouped with rock using species due to its recent acquisition of burrows as shelters.

\section{8 | Retinal maps}

A custom written Matlab (Mathworks, Nattick, Massachusetts) script was used to extract the cell density (cells $/ \mathrm{mm}^{2}$ ) data and retinal outline from the xml file generated by Stereolnvestigator (MBF Bioscience, Williston, Vermont). A thin plate spline was then used to interpolate cell density at $20 \mu \mathrm{m}$ intervals with a second-order polynomial and a lambda value of zero (Garza-Gisholt, Hemmi, Hart, \& Collin, 2014; Hemmi \& Grünert, 1999). A set of iso-density lines was then plotted on the retinal map to visualize the distribution of retinal neurons and fill the contours with a graded color map. This allowed us to graphically represent and compare retinal specializations across species.

\section{9 | Spatial resolving power}

The highest SRP is achieved in retinal regions with the highest RGC and photoreceptor densities. In these regions, spatial resolution is limited by the neuronal population (photoreceptor or RGC) with the lowest density (Wässle, 2004). In afoveate retinal specializations, RGCs set the limits of resolution thresholds since there is more than one cone per RGC
(Wässle, 2004). However, in foveate retinal specializations, the lateral displacement of the RGCs around the foveal pit indicates that perifoveal density is a fraction of the actual sampling density, which makes the peak RGC density, an unreliable measure to estimate the spatial resolution afforded by this specialization (Coimbra et al., 2014; Missotten, 1974; Perry \& Cowey, 1988). Furthermore, in some foveae (e.g., primates), the resolution is limited by photoreceptors instead of the RGC population as there are up to four RGCs per photoreceptor (Perry \& Cowey, 1988; Wässle, Grünert, Röhrenbeck, \& Boycott, 1990). Hence, in this study, we use the peak photoreceptor density and eye size to estimate the SRP of the dragon lizard eyes.

To estimate the posterior nodal distance (PND) or focal length of the eye, we multiplied the axial length by 0.67 as the dragon lizard species studied were more active in bright light (Pettigrew, Dreher, Hopkins, McCall, \& Brown, 1988; Schlesinger, Christian, James, \& Morton, 2011). Retinal magnification factor (RMF), which represents the linear distance in millimeters that corresponds to one degree of visual angle, was estimated using the equation below (Pettigrew et al., 1988):

$$
\mathrm{RMF}=2 \pi \mathrm{PND} / 360
$$

The upper limits of SRP as determined by the highest Nyquist frequency $\left(f_{N}\right)$ was estimated using the following equation (Snyder \& Miller, 1977):

$$
f_{N}=0.5 \times \operatorname{RMF} \times(2 D / \sqrt{3})^{1 / 2}
$$

where $f_{N}$ is given in cycles per degree and $D$ is the peak photoreceptor density (cells $/ \mathrm{mm}^{2}$ ).

\section{3 | RESULTS}

\subsection{Number and distribution of photoreceptors and neurons in the retinal ganglion cell layer}

The eyes of all six Ctenophorus species showed a band of diffuse yellow pigment across the equator of the retina and a central pit indicating the presence of a fovea. Double cones and single cones were confined to a single layer within the photoreceptor layer while

\begin{tabular}{|c|c|c|c|c|c|}
\hline Shelter type & Species & Axial length $(\mathrm{mm} \pm S D)$ & Retinal area $\left(\mathrm{mm}^{2} \pm S D\right)$ & $\begin{array}{l}\text { Total number of } \\
\text { photoreceptors }( \pm S D)\end{array}$ & Total RGCL neurons $( \pm S D)$ \\
\hline \multirow[t]{3}{*}{ Burrows } & C. gibba & $5.63 \pm 0.39, n=4$ & $66.8 \pm 3.0, n=5$ & $2,106,500 \pm \mathrm{n} / \mathrm{a}, n=2$ & $923,667 \pm 119,236, n=3$ \\
\hline & C. nuchalis & $6.59 \pm 0.32, n=3$ & $84.8 \pm 8.2, n=3$ & $3,095,500 \pm \mathrm{n} / \mathrm{a}, n=2$ & $1,302,000 \pm \mathrm{n} / \mathrm{a}, n=2$ \\
\hline & C. pictus & $4.93 \pm 0.31, n=4$ & $51.6 \pm 3.5, n=4$ & $1,460,500 \pm \mathrm{n} / \mathrm{a}, n=2$ & $736,000 \pm 92,698, n=3$ \\
\hline \multirow[t]{4}{*}{ Rocks } & C. ornatus & $4.88 \pm 0.25, n=3$ & $53.5 \pm \mathrm{n} / \mathrm{a}, n=2$ & $1,257,000 \pm n / a, n=1$ & $613,000 \pm \mathrm{n} / \mathrm{a}, n=1$ \\
\hline & C. decresii & $5.29 \pm 0.56, n=4$ & $53.6 \pm 7.1, n=4$ & $1,357,500 \pm n / a, n=2$ & $693,000 \pm 116,503, n=3$ \\
\hline & C. vadnappa & $5.21 \pm 0.32, n=4$ & $58.5 \pm 5.8, n=4$ & $1,514,000 \pm n / a, n=1$ & $843,000 \pm 78,734, n=3$ \\
\hline & Mean $\pm S D$ & $5.42 \pm 0.63$ & $61.5 \pm 12.7$ & $1,798,500 \pm 701,421$ & $851,778 \pm 246,404$ \\
\hline
\end{tabular}

TAB LE 4 Variation in eye size and cell numbers across species

Abbreviation: RGCL, retinal ganglion cell layer. 
neurons in the RGC layer were stacked in 5-6 layers. The total number of photoreceptors was (on average) 2.1 times the total number of RGCLn (Table 4).

The topographic maps of both photoreceptor and RGCLn density confirmed the presence of a steep fovea in the center of the horizontal visual streak. This arrangement was similar in both the photoreceptor and RGC layers across all species examined (Figures 3 and 4). The topographic maps of two burrow-dwelling species (C. nuchalis and C. gibba) also illustrated an iso-density line of 50,000 photoreceptors $/ \mathrm{mm}^{2}$ extending into the ventral retina suggesting a dorsoventral asymmetry in photoreceptor density (Figure 3b,c). This is not readily observed in the topographic maps of the remaining species and does not appear in the distribution of cells within the RGCL (Figure 4). Comparisons of neuronal densities across retinal regions and across rock- and burrowdwelling groups allow for a better understanding of retinal asymmetries. (a)

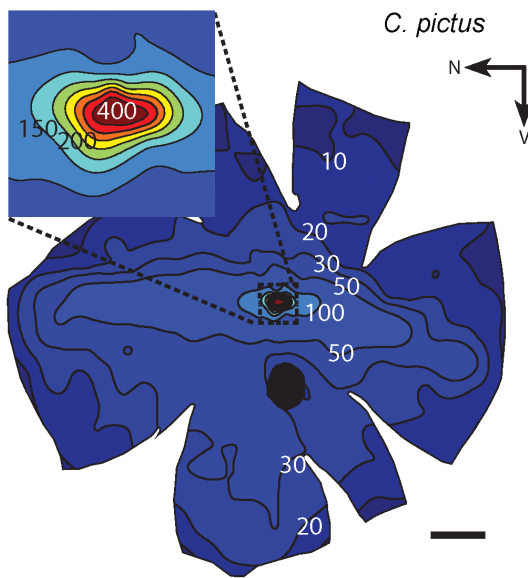

(c)

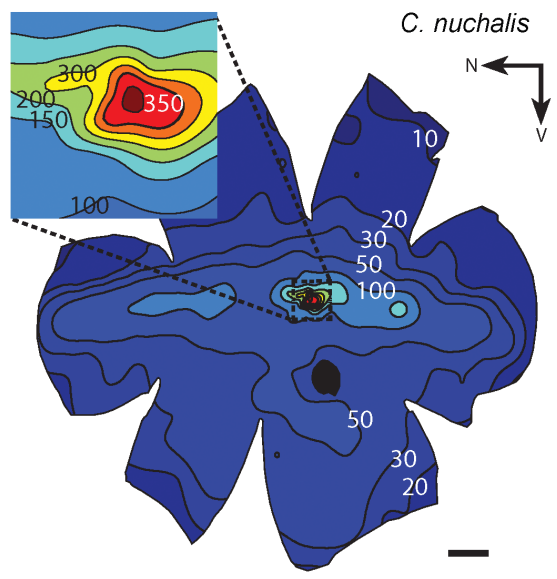

(e)

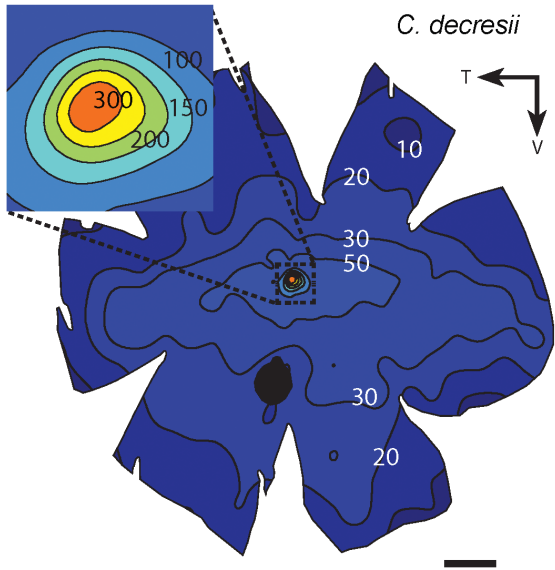

(b)

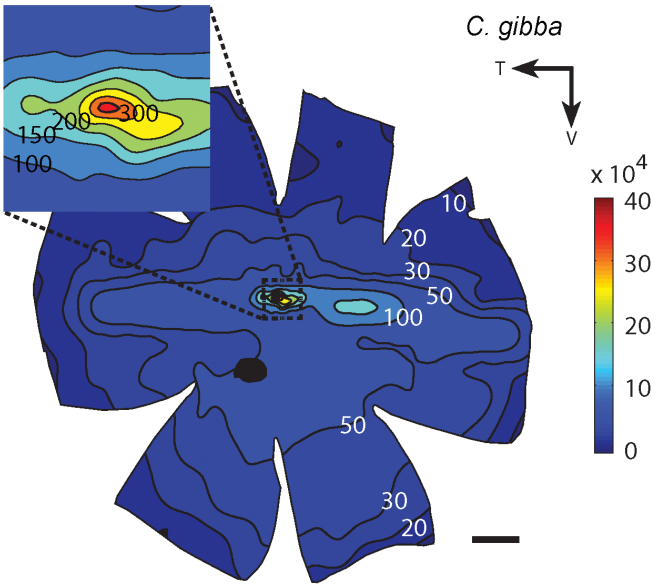

(d)

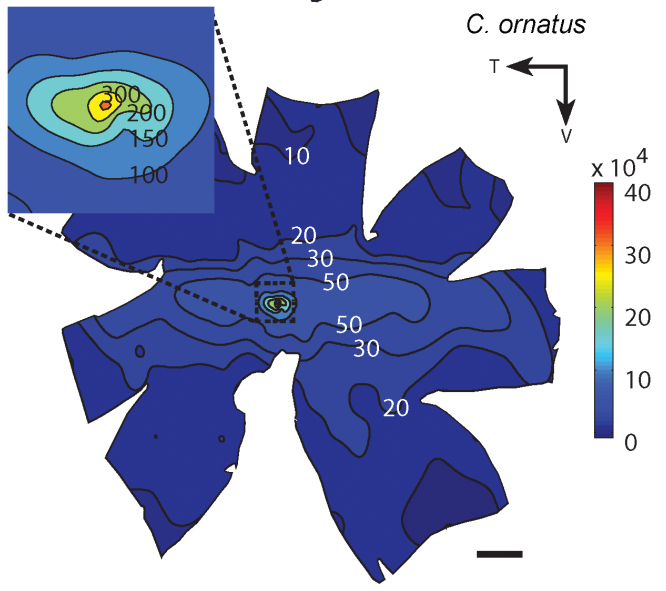

(f)

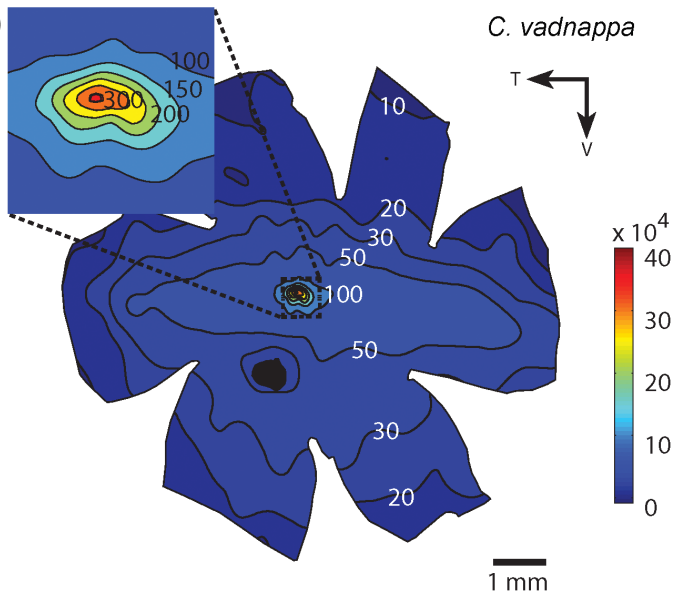

FIGURE 3 Topographic maps of photoreceptor distribution in (a) C. pictus, (b) C. gibba, (c) C. nuchalis, (d) C. ornatus, (e) C. decresii, and (f) C. vadnappa. $\mathrm{N}, \mathrm{T}$, and $\mathrm{V}$ indicate the nasal, temporal, and ventral regions of the retina, respectively. The black circular areas within the retinae illustrate the optic nerve head. All scale bars are at $1 \mathrm{~mm}$, as shown in (f). Iso-density lines in maps and insets indicate cell density in $\times 1,000$ cells/ $\mathrm{mm}^{2}$ and the insets share the same color scale as the maps [Color figure can be viewed at wileyonlinelibrary.com] 
(a)

(c)
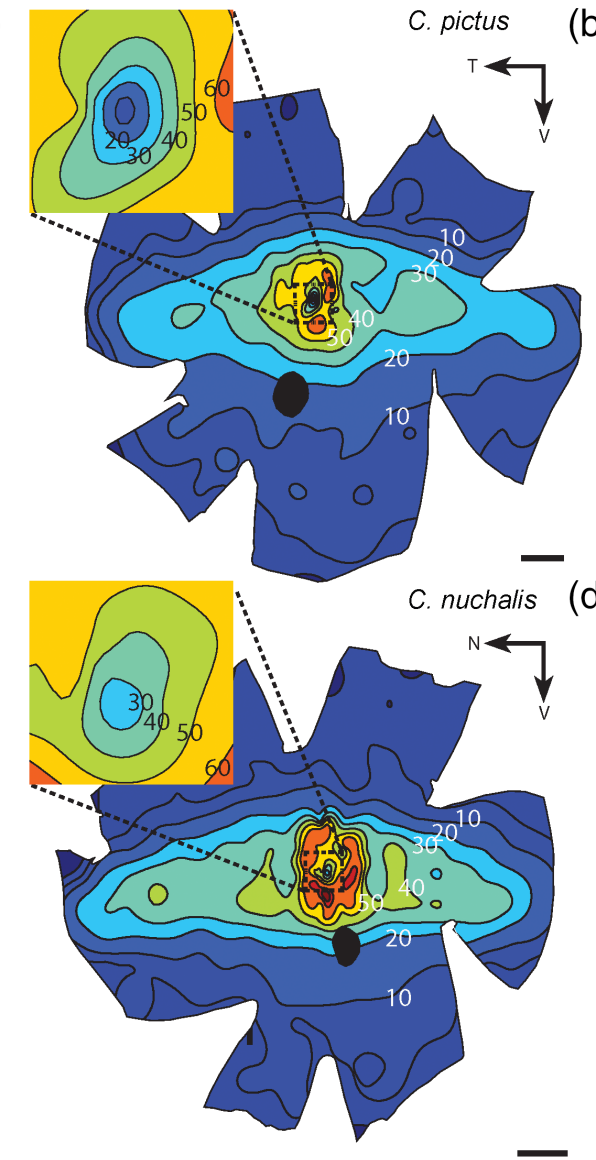

(e)

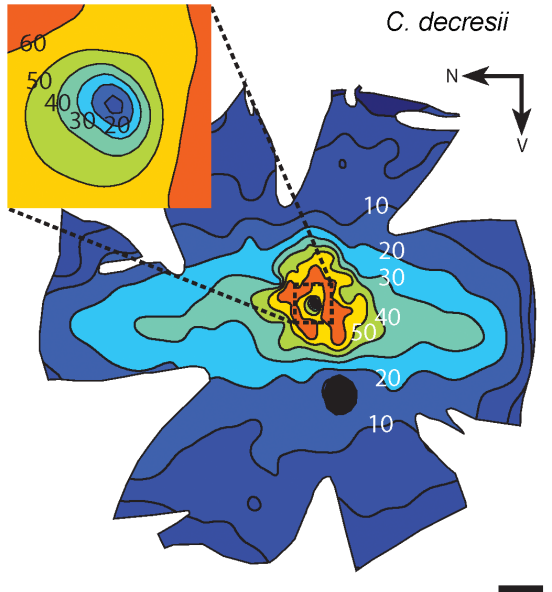

(b)

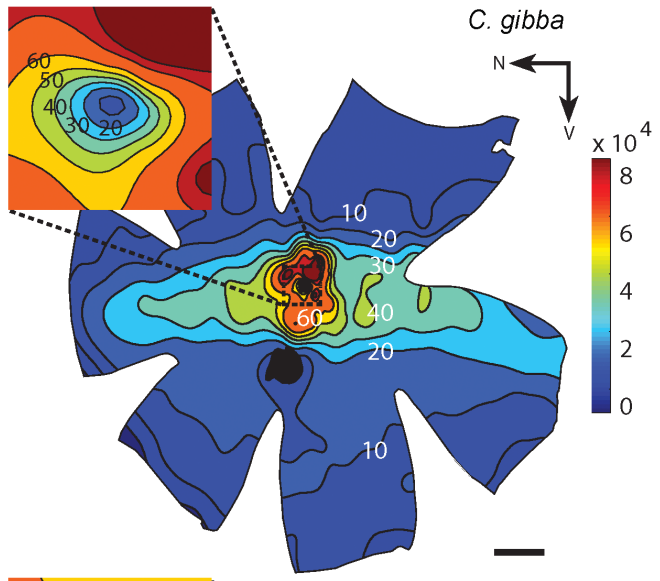

(d)

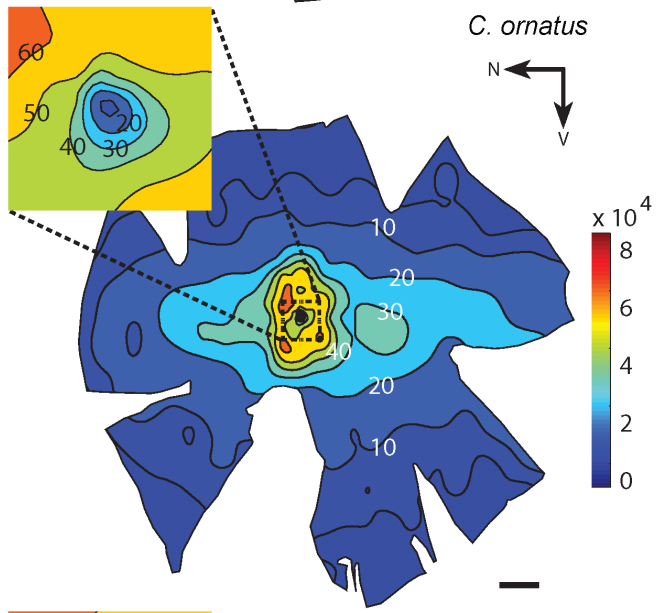

(f)

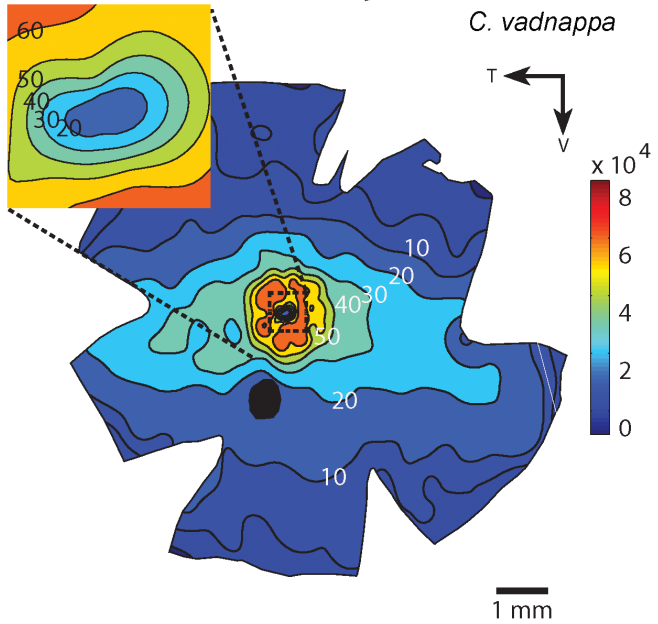

FIGURE 4 Topographic maps of RGCLn distribution in (a) C. pictus, (b) C. gibba, (c) C. nuchalis, (d) C. ornatus, (e) C. decresii, and (f) C. vadnappa. $\mathrm{N}, \mathrm{T}$, and $\mathrm{V}$ indicate nasal, temporal, and ventral regions of the retina, respectively, for orientation purposes. The black circular areas within the retina illustrate the optic nerve head. All scale bars are at $1 \mathrm{~mm}$, as shown in (f). Iso-density lines in maps and insets indicate cell density in $\times 1000$ cells $/ \mathrm{mm}^{2}$ and the insets share the same color scale as the maps. RGCLn, retinal ganglion cell layer neurons [Color figure can be viewed at wileyonlinelibrary.com]

\subsection{Average cell densities and retinal traits across retinal regions and shelter type}

At both central ( $<1 \mathrm{~mm}$ away from foveal center) and peripheral ( $>1 \mathrm{~mm}$ and $<3.5 \mathrm{~mm}$ away from foveal center) regions, photoreceptor and RGCLn densities were compared along dorsoventral and nasotemporal axes. Except for the RGCLn density in the central retina
(Figure 5g), all other RGCLn and photoreceptor densities were significantly higher in the ventral retina compared to the dorsal retina (Ime, $d f=1, p<<.001$, Model $\mathrm{m}$ in Table S1, Figure 5a,c,e). For both photoreceptors and RGCLns, the dorsoventral asymmetry was more pronounced in the periphery compared to the central retina (Ime, $d f=1, p<<.001$, Model $m$ in Table S1, Figure 5a vs. e and Figure $5 c$ vs. g). 

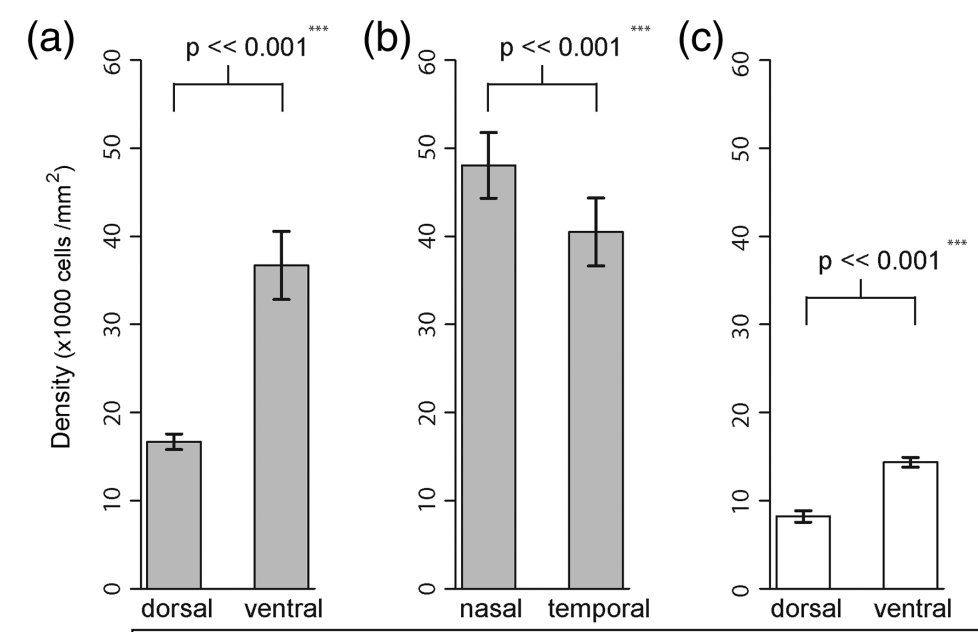

(d)

Peripheral retina

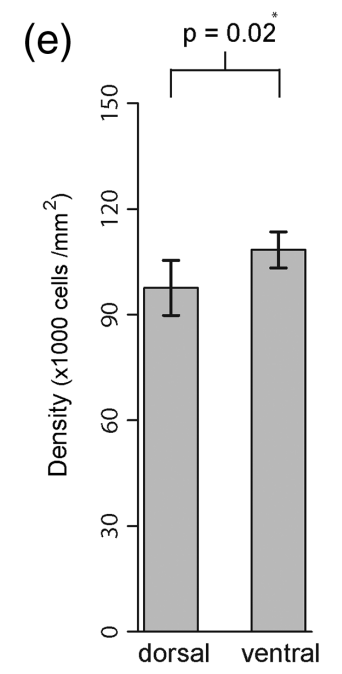

(f) $\quad p=0.94 \quad$ (g)

(h)
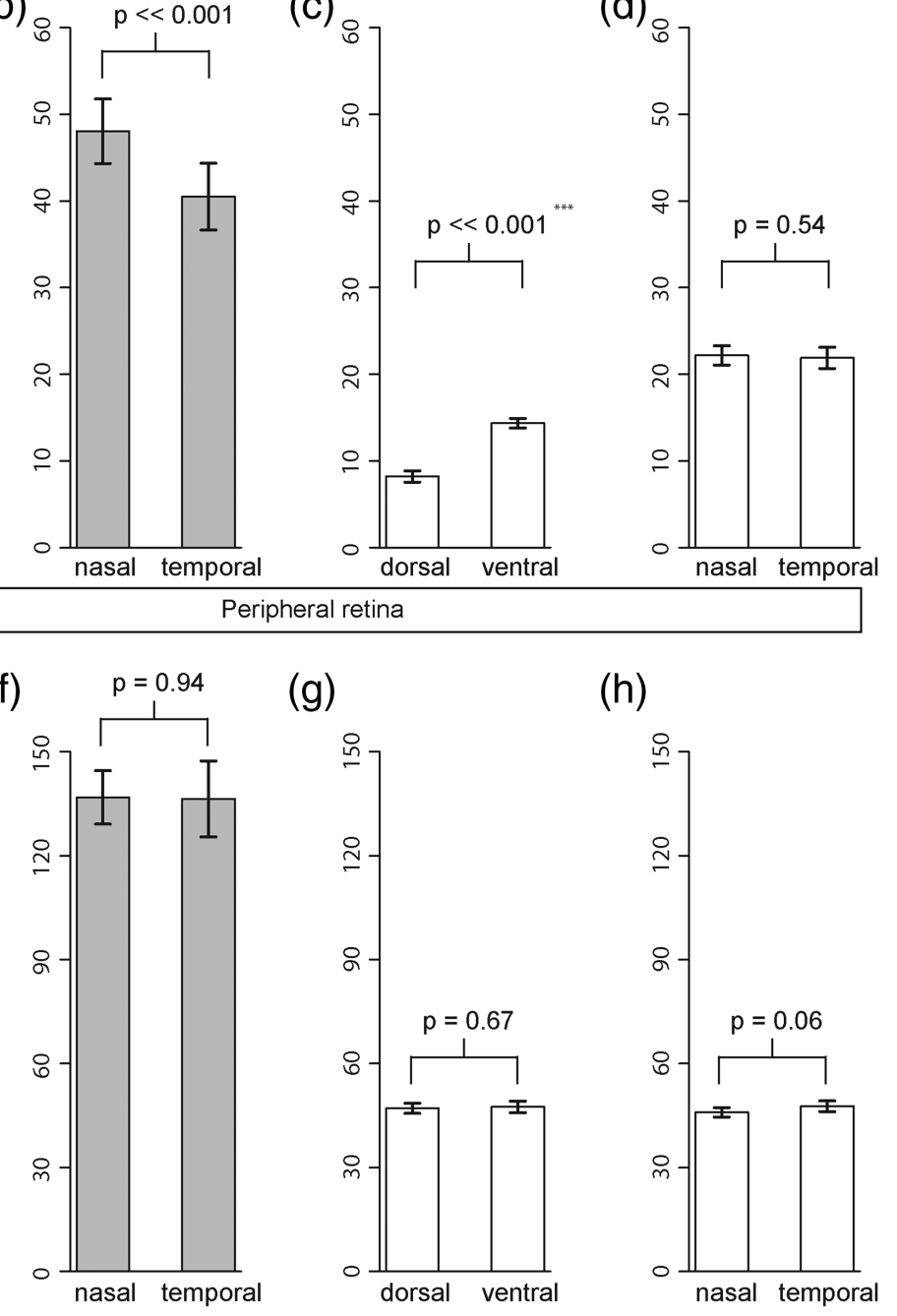

Central retina

Photoreceptor layer $\square$ RGC layer

FIGURE 5 Average cell densities for the peripheral (a-d) and central (e-h) retina across six Ctenophorus species. (a) Photoreceptor density in the dorsal and ventral peripheral retina. (b) Photoreceptor density in the nasal and temporal peripheral retina. (c) RGCLn density in the ventral and dorsal peripheral retina. (d) RGCLn density in the nasal and temporal peripheral retina. (e) Photoreceptor density in dorsal and ventral central retina. (f) Photoreceptor density in the nasal and temporal central retina. (g) RGCLn in the dorsal and ventral central retina. (h) RGCLn in the nasal and temporal central retina. RGCLn, retinal ganglion cell layer neurons

There were no significant differences in photoreceptor and RGCLn densities along the nasotemporal axis except for an $18.7 \%$ higher photoreceptor density in the nasal periphery compared to the temporal periphery (Ime, $d f=1, p<<.001$, Model o in Table S1, Figure 5b).

For photoreceptors, there was a clear difference in the strength of the dorsoventral asymmetry in the peripheral retina across shelter type. The asymmetry is significantly stronger in burrow-dwelling species compared to rock-dwelling species $(\mathrm{Im}, d f=1, p<<.001$, Model q in Table S1, Figure 6a). No such difference was found for RGCLns (Im, $d f=1, p=.177$, Model $r$ in Table S1, Figure 6b). Besides possessing a stronger dorsoventral asymmetry, burrow-dwelling species also have larger eyes with significantly longer axial lengths and larger retinal areas (Ime/lm, $d f=1, p<.001$, Models b and $\mathrm{c}$ in Table S1, Figure 6c, d). The peak photoreceptor density, however, remains the same across shelter type ( $\mathrm{Im}, d f=1, p>.05$, Model $\mathrm{f}$ in Table S1, Figure 6e).

\section{3 | Spatial resolving power}

Peak photoreceptor and RGCLn densities did not differ between rock- and burrow-dwelling species $(\mathrm{Im}, d f=1, p>.05$, Models $f$ and $g$ in Table S1). An average peak photoreceptor density of 401,100 $\pm 31,033$ photoreceptors $/ \mathrm{mm}^{2}$ (mean $\pm S D$ ) with an axial length of the eye ranging from 4.8 to $6.4 \mathrm{~mm}$ provided SRP estimates ranging from 19 to 26 cycles/degree across the six Ctenophorus species (Table 5). Although there was no difference in peak photoreceptor density across shelter type (Models $f$ and $g$ in Table S1), species that burrowed had a significantly longer axial length $(6.04 \pm 0.61 \mathrm{~mm}$, 

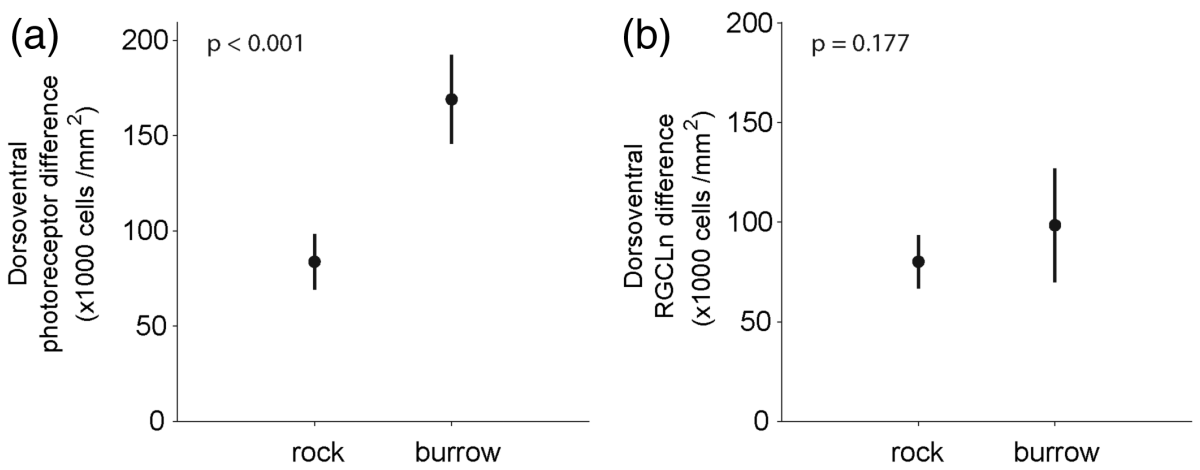

(c)

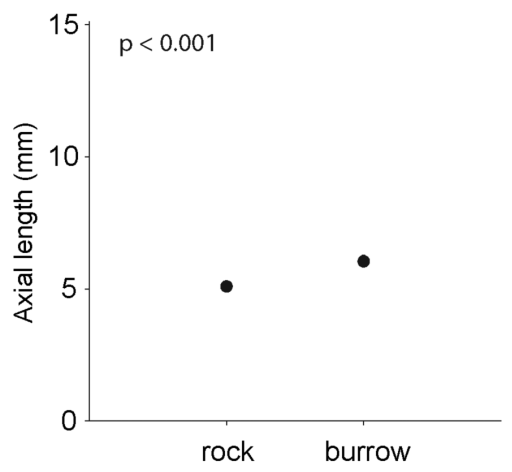

(e)

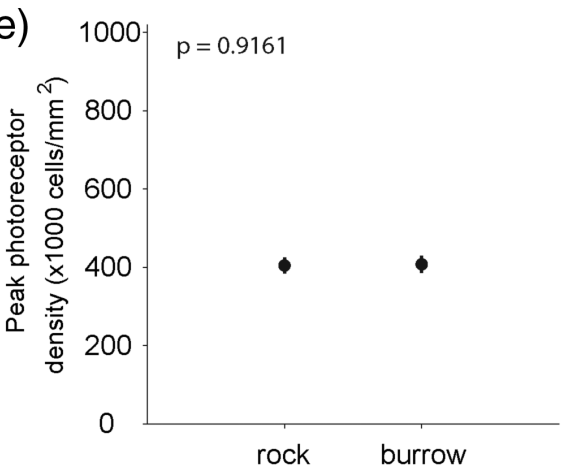

(d)

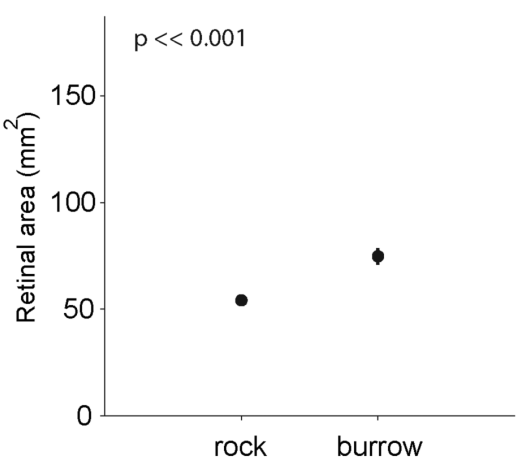

(f)

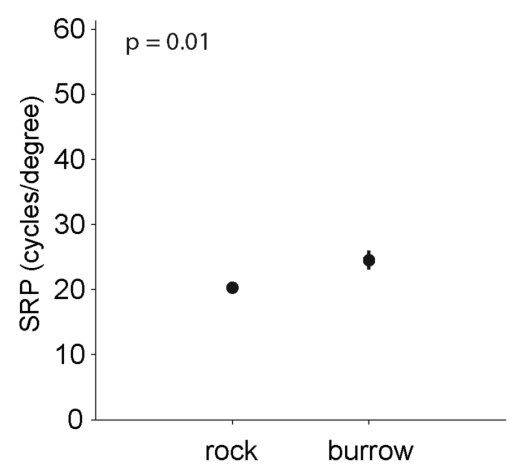

FIGURE 6 Comparison of retinal traits across shelter type from six Ctenophorus species. (a) Differences in the density of photoreceptors along the dorsoventral axis in the peripheral retina. (b) Differences in the density of RGCLn along the dorsoventral axis in the peripheral retina. (c) Axial length of the eye across shelter type. (d) Retinal area across shelter type. (e) Peak photoreceptor density across shelter type. (f) Spatial resolving power across shelter type. Vertical bars indicate $S E$. Y-axes limits have been set from 0 to 2.5 times the value of rock-dwelling groups, so slopes can be compared between graphs. RGCLn, retinal ganglion cell layer neurons

TAB LE 5 Spatial resolving power calculated using mean peak photoreceptor density and mean axial length

\begin{tabular}{|c|c|c|c|c|c|c|}
\hline Species & $\begin{array}{l}\text { Axial } \\
\text { length (mm) }\end{array}$ & PND (mm) & $\begin{array}{l}\text { RMF } \\
\text { (mm/degree) }\end{array}$ & $\begin{array}{l}\text { Peak RGC density } \\
\text { (cells } / \mathrm{mm}^{2} \text { ) }\end{array}$ & $\begin{array}{l}\text { Peak photoreceptor density } \\
\text { (cells } / \mathrm{mm}^{2} \text { ) }\end{array}$ & $\begin{array}{l}\text { SRP from } \\
\text { photoreceptors } \\
\text { (cycles/degree) }\end{array}$ \\
\hline C. gibba & $5.63 \pm 0.39$ & 3.78 & 0.07 & $83,167 \pm 12,000$ & $397,800 \pm 53,000$ & 22 \\
\hline C. nuchalis & $6.59 \pm 0.32$ & 4.25 & 0.07 & $78,750 \pm 9,000$ & $417,750 \pm 50,000$ & 26 \\
\hline C. pictus & $4.93 \pm 0.31$ & 3.23 & 0.06 & $71,667 \pm 4,000$ & $453,300 \pm 69,000$ & 20 \\
\hline C. vadnappa & $5.21 \pm 0.32$ & 3.59 & 0.06 & $70,000 \pm 8,000$ & $391,100 \pm-$ & 21 \\
\hline Mean $\pm S D$ & $5.42 \pm 0.63$ & $3.60 \pm 0.38$ & $0.06 \pm 0.01$ & $74,764 \pm 7,000$ & $401,100 \pm 31,000$ & $21 \pm 2$ \\
\hline
\end{tabular}

Abbreviations: PND, postnodal distance; RGC, retinal ganglion cell; RMF, retinal magnification factor; SD: standard deviation, average values are illustrated by mean $\pm S D$; SRP, spatial resolving power, assuming hexagonal packing of neurons. 


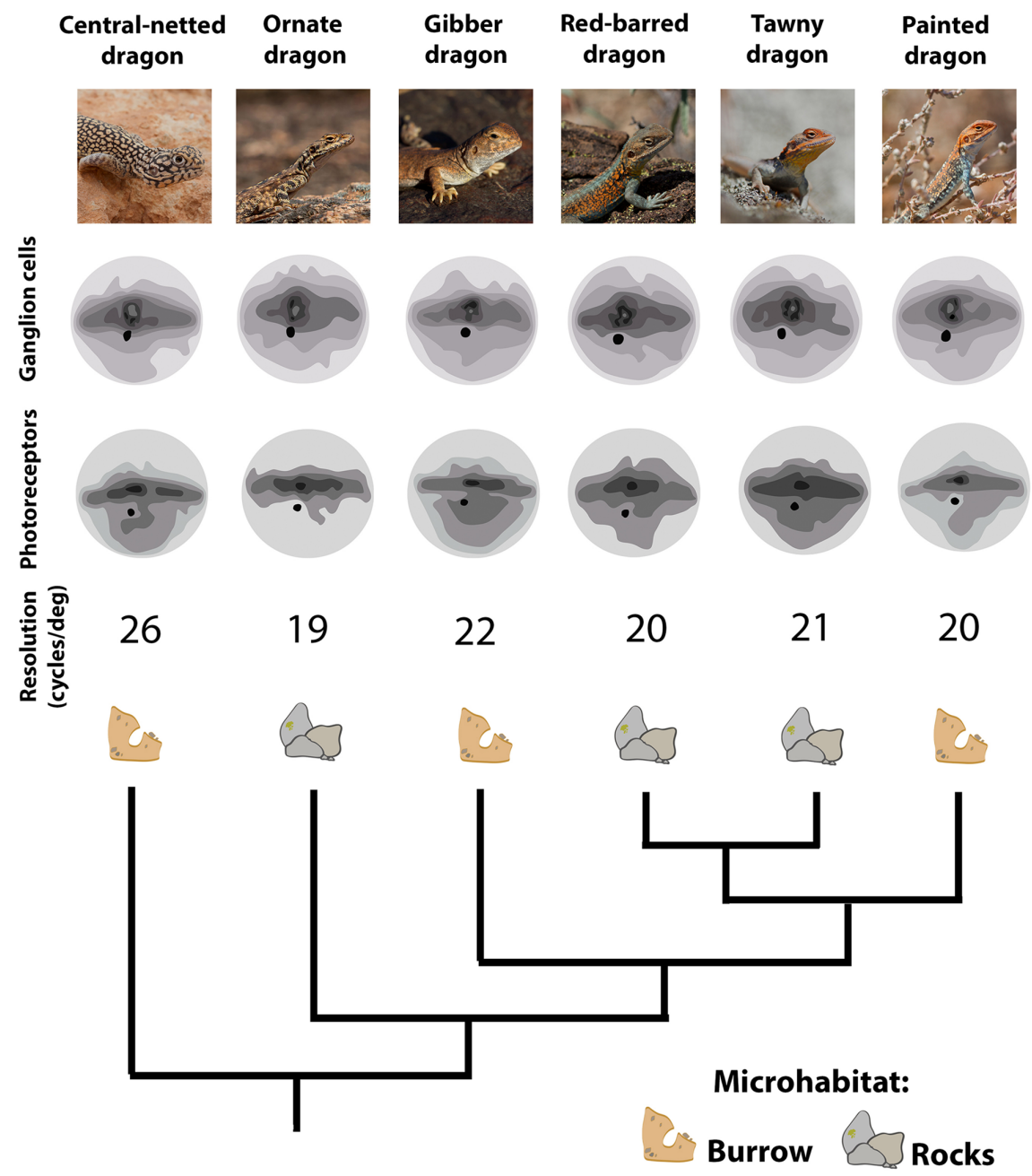

FIGURE 7 Summary of data on the topographic distribution of neurons (photoreceptors and RGCLns), spatial resolution, and shelter type of six species of dragon lizards examined in this study. RGCLn, retinal ganglion cell layer neurons [Color figure can be viewed at wileyonlinelibrary.com]

Figure 6c, Im, $d f=1, p<.001$, Model $\mathrm{c}$ in Table S1) and therefore a higher SRP $(24.5 \pm 2.9$ cycles/degree, $\mathrm{Im}, d f=1, p=.01$, Model $\mathrm{h}$ in Table S1, Figure 6f).

\section{4 | DISCUSSION}

All dragon lizard species examined here have a horizontal visual streak along the retinal meridian, with a central convexiclivate fovea revealed by the topographic distribution of neurons in the ganglion cell layer and photoreceptors (Figure 7). A unique feature found in our study is a strong dorsoventral asymmetry in photoreceptor density, which was higher in the ventral retina than in the dorsal retina, especially in the region outside the central fovea. The high number of photoreceptors in the ventral retina indicates increased spatial summation potentially mediating higher sensitivity in the dorsal visual field compared to the ventral visual field. The ecological niches and shelter type of dragon lizards are evolutionarily stable traits. Inhabiting sandy ridges and using burrows as shelter appears to be ancestral. In contrast, living among rocks and using rock fissures and crevices as shelter has evolved independently several times across the Ctenophorus genus (Figure 7). Here, we reveal that species possessing the ancestral trait of using burrows for shelter have significantly larger eyes, higher total number of photoreceptors and RGCLn, higher ventral photoreceptor densities, and higher SRP than rock-dwelling species (Figure 7).

\subsection{Conserved retinal specializations in dragon lizards: Differences and similarities}

Two retinal specializations are strongly conserved in the Ctenophorus species of our study: the centrally located fovea and the horizontal visual streak across the retinal equator. A third retinal specialization, the dorsoventral asymmetry of retinal neurons, is more variable among species and is discussed in more detail further below. The location of the fovea and the lateral placement of dragon lizard eyes suggest that the highest visual acuity is achieved in the center of the monocular visual field on either side of the head. The weak ocular 
muscles observed during enucleation of all species suggest that eye movements are not frequent. Instead, dragon lizards may rely on head movements to align the fovea with objects of interest for detection of fine details. The visual streak is slightly vertically elongated and its horizontal elongation across the width of the retina enables higher SRP across the visual horizon. In an open environment, the horizon dominates the visual field and is the location where predator approaches can first be detected. Hence, the enhanced visual acuity provided by the horizontal streak along the visual horizon may be ecologically advantageous (Hughes, 1977) in the arid and semiarid environments inhabited by these lizards (Greer, 1989).

The presence of a horizontal streak and a central fovea in the central-netted (C. nuchalis) and ornate ( $C$. ornatus) dragon lizards contradicts the findings of two previous studies that examined the same species (Figures 3 and 4). Wilhelm and Straznicky (1992) found a horizontal streak but not a fovea in the central-netted dragon, while Barbour et al. (2002) found a fovea but not a horizontal streak in the ornate dragon lizard. These discrepancies highlight the importance of having an appropriate stereological sampling protocol in the reconstruction of the topographic features of the retina. Wilhelm and Straznicky used $150 \times 150 \mu \mathrm{m}^{2}$ counting frames across the entire retina, and these were likely too large to reveal a small feature with a steep increase in cell density like the fovea. In contrast, Barbour et al. (2002) found a fovea in the ornate dragon, but the use of subsampled sections to create an average of the retinal distribution makes it very difficult to identify the horizontal streak, which is common among the dragon lizards studied here (Coimbra et al., 2015; Curcio \& Allen, 1990; Jamieson \& Fisher, 1971; Landau \& Dawson, 1970; Mass \& Supin, 1992, 2003, 2005; Nagy \& Ronald, 1970).

The high degree of similarity of the fovea and the horizontal streak among the six species studied here suggests that these are conserved topographic features of the retina across ecological niches and that they are likely shared by other Ctenophorus species. While independent eye movements in chameleons (Hews, Castellano, \& Hara, 2004; Watt \& Joss, 2003) and the lateralization of visually mediated behaviors in lizards has received some attention (Katz et al., 2015; Ott, 2001), the relevance of specific retinal regions and therefore the regions of the visual field which they subtend remains poorly understood. This novel information on the topographic specialization of neuron density in the retina of Ctenophorus species provides a solid anatomical foundation for future behavioral experiments exploring visually mediated behaviors across the visual field.

\section{2 | SRP in dragon lizards: Ecological relevance}

SRP mediated by the fovea ranges from 19 to 26 cycles/degree in all species, providing them with the capacity to potentially resolve objects as small as $2.3-1.7 \mathrm{~mm}$ at $0.5 \mathrm{~m}$ given that they also have optimal contrast and luminance, and that the animal has the appropriate contrast sensitivity. This SRP is high enough for the detection of small insects, which make up most of their diet. The SRP of other agamids has not been measured, although based on a previous study on the eye of the green anole (Anolis carolinensis) by Makaretz and Levine (1980), we can compare the anatomical estimates of visual acuity in this study to another similarly sized lizard. The green anole has a peak photoreceptor density of 290,000 cells $/ \mathrm{mm}^{2}$ and an estimated axial length and PND of $4.2 \mathrm{~mm}$ and $2.8 \mathrm{~mm}$, respectively. Assuming that the photoreceptors are hexagonally packed, the anatomical estimate of the visual acuity of the green anole is $14.2 \mathrm{cycles} /$ degree compared to the $21 \pm 2$ cycles/degree (mean $\pm S D$ ) estimated in the dragon lizard species. This difference in SRP is the product of a larger PND $(3.6 \pm 0.4)$ and a higher peak density of photoreceptors $\left(401,000 \pm 31,033\right.$ cells $\left./ \mathrm{mm}^{2}\right)$ in the dragon lizard species compared to the green anole. The only other lizard for which the visual acuity has been anatomically estimated is the sleepy lizard (Tiliqua rugosa) which does not possess a fovea (New \& Bull, 2011). Although the sleepy lizard eye has a PND twice $(6.25 \mathrm{~mm}$, New \& Bull, 2011) that of the estimates for the dragon lizards, the low peak RGC density of 15,500 cells $/ \mathrm{mm}^{2}$ yields a SRP of 7.3 cycles/degree (recalculated assuming hexagonally packed RGCs). Despite the scarce knowledge on lizard visual acuity, the eyes of dragon lizards appear to be specialized for higher visual acuity compared to other lizard species examined to date. Interestingly, peak photoreceptor density estimated for dragon lizards is remarkably similar to peak photoreceptor density estimates $\left(320,000-440,000\right.$ cells $\left./ \mathrm{mm}^{2}\right)$ for visually oriented passerine birds with similar eye size (Coimbra et al., 2015), suggesting that high resolution is important for the ecology and behavior of dragon lizards.

\section{3 | Dorsoventral asymmetries in the distributions of retinal ganglion cells and photoreceptors: Functional implications}

All dragon lizards studied here are terrestrial (Ramos \& Peters, 2015). Given their small body size, the eyes of these dragon lizards are very

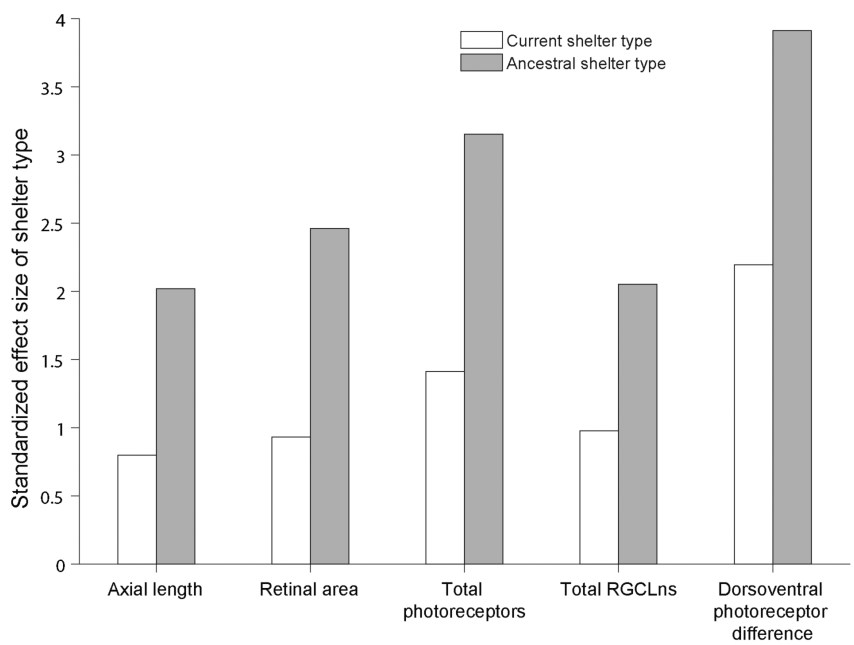

FIGURE 8 The standardized effect size of shelter on retinal traits for ancestral and current shelter type across. Effect size has been standardized using the pooled SD as described by Cohen (1988) 
$\triangle$ Direct ancestor: Burrower

o Direct ancestor: Non-burrower

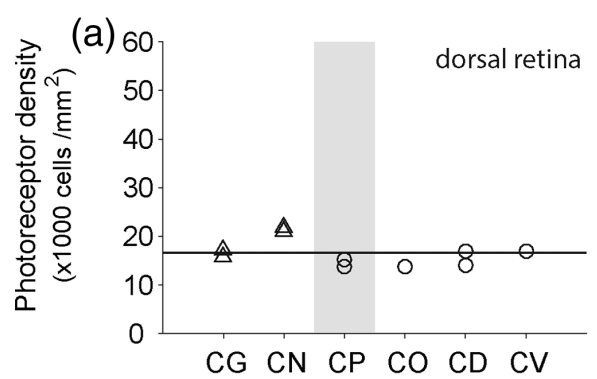

C. pictus recently acquired burrowing

(b)

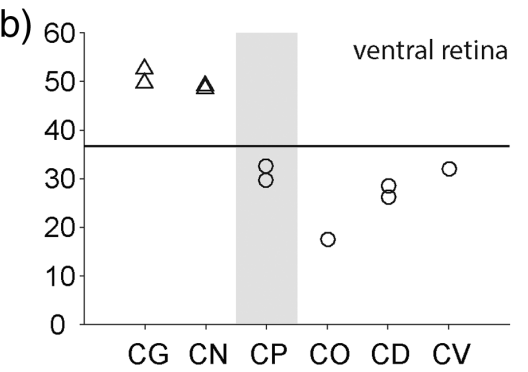

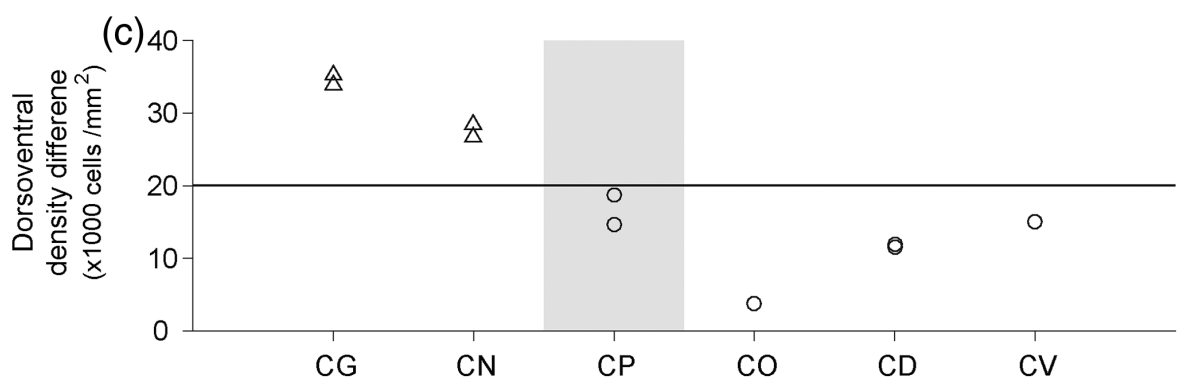

FIGURE 9 Photoreceptor densities across species in the dorsal and ventral region and the difference between them. (a) Average dorsal photoreceptor density, (b) average ventral photoreceptor density, (c) average dorsoventral difference in photoreceptor density. The black line in $(a-c)$ indicates the mean of the $y$-axis values. CD, C. decresii; CG, C. gibba; CN, C. nuchalis; CO, C. ornatus; CP, C. pictus; CV, C. vadnappa

close to the ground. This proximity to the ground yields an asymmetric visual field where the ventral visual field is dominated by the ground close to the animal and the rest of the world is seen in the central and dorsal visual field. This results in most relevant visual cues occurring in visual space subtended by the central and ventral retinal regions and this appears to be reflected by dorsoventral asymmetric densities of photoreceptors and RGCLn. Although both photoreceptor and RGCLn densities are higher in the ventral retina, the photoreceptor density is greater than RGCL neuronal density, resulting in greater convergence of photoreceptors to retinal ganglion cells in the ventral retina. This increased convergence is often associated with the spatial summation of signals across photoreceptors in order to increase the signal to noise ratio. In animals living in low-light conditions, this configuration is thought to increase light sensitivity (Locket, 1977). However, the dragon lizards studied here are strictly diurnal and the visual system is not light-limited. An alternative hypothesis might be that spatial summation could be used to increase contrast sensitivity to facilitate the detection of relevant visual cues in the dorsal visual field.

Aerial predators such as kestrels, kookaburras and corvids, which approach from the dorsal visual field, are known to prey on dragon lizards (Teasdale et al., 2013). The evolutionary pressure of these aerial predators is evident in asymmetric body coloration that often provides camouflage as is the case in the red-barred (C. vadnappa) and the tawny (C. decresii) dragons (Gibbons \& Lillywhite, 1981). It is possible that the similar selective pressures that result in asymmetric body coloring are also responsible for asymmetric retinal features thereby facilitating camouflage and predator detection, respectively. Given the use of complex motion-based signals in many dragon lizards (Peters \& Evans 2003, Ramos \& Peters, 2015), conspecific signal detection could also be the driving force for dorsoventral retinal asymmetry; however, little is known about signaler and receiver orientation to determine whether this is plausible.

\subsection{Ancestral shelter type and retinal traits}

In the burrow-dwelling group, the evolutionary lineage including the Gibber (C. gibba) and the central-netted (C. nuchalis) dragons have used burrows as shelters throughout their evolutionary history while the painted dragon (C. pictus) lineage has only recently reacquired the use of burrows (Melville, Schulte, \& Larson, 2001). It is thus interesting to note that the painted dragon has the smallest eye, lowest number of retinal neurons, and lowest SRP compared to the two other burrow-using species examined. Due to these features, the eyes of the painted dragon resemble the eyes of rock-dwelling species despite being a burrow-dweller. Although the evolution of an eye can occur in a very short time, the speed of adaptation depends on the strength of the selective pressure (Nilsson \& Pelger, 1994). C. pictus eyes retaining similar features to the eyes of rock-dwelling species despite 9 million years of divergence may indicate the absence of a strong selective pressure to reacquire the larger eye and more densely packed retina found in other burrow-dwelling species (Melville et al., 2001). Grouping species by ancestral shelter type instead of their current shelter type produces a stronger standardized effect size of shelter type on retinal traits (Figure 8). This suggests that ancestral shelter type may be the better predictor of retinal traits such as eye size, photoreceptor and RGCLn numbers, and dorsoventral differences in neuronal density (Figure 8). The dorsoventral asymmetry, which is a previously uncharacterized topographic feature of lizard retinae, is more pronounced in the photoreceptor layer than in the RGCL. This strong asymmetry in the density of photoreceptors is driven by an increased 
photoreceptor density in the ventral region of the retina. Furthermore, species with a burrow-dwelling ancestor had higher ventral photoreceptor densities, while dorsal photoreceptor densities remained similar across all species (Figure 9). This suggests that phylogenetic pressures are able to act on photoreceptor densities to shape the topographic features of the retina in Ctenophorus species.

\section{5 | CONCLUSION}

Here, we provided new insight into the factors which can affect retinal organization in lizards and a comprehensive characterization of the retinal regions of several Ctenophorus species. The eyes of dragon lizards (Ctenophorus species) appear specialized for high acuity vision due to elevated photoreceptor density in the fovea compared to other lizard species studied to date. Although the presence of the fovea and the visual streak appears conserved across species, variations in the distribution of retinal neurons suggest that the lizard retina is shaped by a complex set of factors.

Shelter type is a strong predictor of retinal traits such as eye size and retinal neuron density in the Ctenophorus genus. However, the shelter type of the direct ancestor of a species appears to be a better predictor than the current shelter type. This phylogenetic pressure seems to strongly affect photoreceptor densities in the ventral retina thereby contributing to the retinal organization of Ctenophorus species.

The standardized methods used to characterize the retina across the six species of our study have demonstrated the importance of appropriate stereological sampling protocols and aim to provide a more robust platform for future comparative studies of retinal topography in lizards. The well-established phylogeny, the complex set of visually mediated behaviors, and the novel insight into the retinal organization of Ctenophorus species provided here, set the stage for exciting experiments to investigate the mechanisms which drive visual behavior in lizards.

\section{ACKNOWLEDGMENTS}

We would like to thank Caroline Kerr for her help throughout the project. We are also grateful to Professor Philip Withers for several discussions about the ecology and physiology of the genus Ctenophorus. Our gratitude is also extended to Peter Derbyshire and Dr. James O'Shea who donated samples for the Ctenophorus ornatus specimens. We are grateful to field assistants Angus Kennedy and Tobias Hayashi for providing the pictures in Figure 1. We are also grateful to Professor Scott Keogh for facilitating the collection of dragon lizards.

\section{CONFLICT OF INTEREST}

The authors have no conflict of interest in this study.

\section{AUTHOR CONTRIBUTIONS}

The authors had full access to all the data in the study and take responsibility for the integrity of the data and the accuracy of the data analysis. Study concept and design: N.N., J.P.C., N.S.H., S.P.C., and J.M.H.; Collection of specimens: D.H.; Collection and acquisition of data: N.N.; Analysis and interpretation of the data: N.N., J.P.C., and J.M.H.; Writing of the manuscript: N.N.; Critical revision of the manuscript for important intellectual content: D.H., J.P.C., N.S.H., S.P.C., and J.M.H.; Obtained funding: N.S.H., S.P.C., and J.M.H.

\section{DATA AVAILABILITY STATEMENT}

The data that support the findings of this study are available from the corresponding author upon reasonable request.

\section{ORCID}

Nicolas Nagloo (D) https://orcid.org/0000-0002-6564-5737

João Paulo Coimbra (D) https://orcid.org/0000-0001-7972-7429

\section{REFERENCES}

Barbour, H. R., Archer, M. A., Hart, N. S., Thomas, N., Dunlop, S. A., Beazley, L. D., \& Shand, J. (2002). Retinal characteristics of the ornate dragon lizard, Ctenophorus ornatus. Journal of Comparative Neurology, 450, 334-344.

Bates, D., Maechler, M., Bolker, B., \& Walker, S. (2015). Fitting linear mixedeffects models using Ime4. Journal of Statistical Software, 67, 1-48.

Cohen, J. (1988). The t-test for means. In Statistical power analysis for the behavioral sciences (p. 44). Hillsdale, NJ: Lawrence Erlbaum Associates.

Coimbra, J. P., Bertelsen, M. F., \& Manger, P. R. (2017). Retinal ganglion cell topography and spatial resolving power in the river hippopotamus (Hippopotamus amphibius). Journal of Comparative Neurology, 525, 2499-2513.

Coimbra, J. P., Collin, S. P., \& Hart, N. S. (2014). Topographic specializations in the retinal ganglion cell layer correlate with lateralized visual behavior, ecology, and evolution in cockatoos. Journal of Comparative Neurology, 522, 3363-3385.

Coimbra, J. P., Collin, S. P., \& Hart, N. S. (2015). Variations in retinal photoreceptor topography and the organization of the rod-free zone reflect behavioral diversity in Australian passerines. Journal of Comparative Neurology, 523, 1073-1094.

Coimbra, J. P., Hart, N. S., Collin, S. P., \& Manger, P. R. (2013). Scene from above: Retinal ganglion cell topography and spatial resolving power in the giraffe (Giraffa camelopardalis). Journal of Comparative Neurology, 521, 2042-2057.

Coimbra, J. P., Marceliano, M. L. V., Andrade-da-Costa, B. L. S., \& Yamada, E. S. (2006). The retina of tyrant flycatchers: Topographic organization of neuronal density and size in the ganglion cell layer of the great kiskadee Pitangus sulphuratus and the rusty margined flycatcher Myiozetetes cayanensis (Aves: Tyrannidae). Brain, Behavior and Evolution, 68, 15-25.

Coimbra, J. P., Pettigrew, J. D., Kaswera-Kyamakya, C., Gilissen, E., Collin, S. P., \& Manger, P. R. (2017). Retinal ganglion cell topography and spatial resolving power in African megachiropterans: Influence of roosting microhabitat and foraging. Journal of Comparative Neurology, 525, 186-203.

Coimbra, J. P., Trévia, N., Marceliano, M. L. V., Andrade-Da-Costa, B. L. S., Picanço-Diniz, C. W., \& Yamada, E. S. (2009). Number and distribution of neurons in the retinal ganglion cell layer in relation to foraging behaviors of tyrant flycatchers. Journal of Comparative Neurology, 514, 66-73.

Collin, S. P. (1999). Behavioural ecology and retinal cell topography. In S. N. Archer, M. B. Djamgoz, E. Loew, J. C. Partridge, \& S. Vallerga 
(Eds.), Adaptive mechanisms in the ecology of vision (pp. 509-535). London, UK: Chapman and Hall.

Curcio, C. A., \& Allen, K. A. (1990). Topography of ganglion cells in human retina. Journal of Comparative Neurology, 300, 5-25.

Detwiler, S., \& Laurens, H. (1920). Studies on the retina. The structure of the retina of Phrynosoma cornutum. Journal of Comparative Neurology, 32, 347-356.

Fite, K. V., \& Lister, B. C. (1981). Bifoveal vision in anolis lizards. Brain, Behavior and Evolution, 19, 144-154.

Garza-Gisholt, E., Hemmi, J. M., Hart, N. S., \& Collin, S. P. (2014). A comparison of spatial analysis methods for the construction of topographic maps of retinal cell density. PLoS One, 9, e93485.

Gibbons, J. R., \& Lillywhite, H. B. (1981). Ecological segregation, color matching, and speciation in lizards of the Amphibolurus decresii species complex (Lacertilia: Agamidae). Ecology, 62: 1573-1584.

Glaser, E., \& Wilson, P. (1998). The coefficient of error of optical fractionator population size estimates: A computer simulation comparing three estimators. Journal of Microscopy, 192, 163-171.

Greer, A. E. (1989). The biology and evolution of Australian lizards. Chipping Norton, New South Wales, Australia: Surrey Beaty and Sons.

Gundersen, H. J. G. (1977). Notes on the estimation of the numerical density of arbitrary profiles: The edge effect. Journal of Microscopy, 111, 219-223.

Hemmi, J. M., \& Grünert, U. (1999). Distribution of photoreceptor types in the retina of a marsupial, the tammar wallaby (Macropus eugenii). Visual Neuroscience, 16, 291-302.

Hews, D. K., Castellano, M., \& Hara, E. (2004). Aggression in females is also lateralized: Left-eye bias during aggressive courtship rejection in lizards. Animal Behaviour, 68, 1201-1207.

Hoops, D. (2015). A perfusion protocol for lizards, including a method for brain removal. MethodsX, 2, 165-173.

Hughes, A. (1977). The topography of vision in mammals of contrasting life style: Comparative optics and retinal organisation. In F. Crescitelli (Ed.), Handbook of sensory physiology. The visual system of vertebrates (Vol. VII/5, pp. 613-756). Berlin, Germany: Springer Verlag.

Jamieson, G. S., \& Fisher, H. D. (1971). The retina of the harbor seal Phoca vitulina. Canadian Journal of Zoology, 49, 19-23.

Katz, H. K., Lustig, A., Lev-Ari, T., Nov, Y., Rivlin, E., \& Katzir, G. (2015). Eye movements in chameleons are not truly independent-evidence from simultaneous monocular tracking of two targets. Journal of Experimental Biology, 218, 2097-2105.

Landau, D., \& Dawson, W. W. (1970). The histology of retinas from the pinnipedia. Vision Research, 10, 691-702.

Laughlin, S. B. (2001). Energy as a constraint on the coding and processing of sensory information. Current Opinion in Neurobiology, 11, 475-480.

Laughlin, S. B., van Steveninck, R. R. D. R., \& Anderson, J. C. (1998). The metabolic cost of neural information. Nature Neuroscience, 1, 36-41.

Locket, N. (1977). Adaptations to the deep seaenvironment. In F.Crescitelli (Ed.), Handbook of Sensory Physiology. (Vol. VII/5, pp. 68-192). Berlin: Springer Verlag.

Losos, J. B. (2011). Lizards in an evolutionary tree: Ecology and adaptive radiation of anoles (Vol. 10). Berkley, California: University of California Press.

Makaretz, M., \& Levine, R. L. (1980). A light microscopic study of the bifoveate retina in the lizard Anolis carolinensis: General observations and convergence ratios. Vision Research, 20, 679-686.

Mass, A. M., \& Supin, A. Y. (1992). Peak density, size and regional distribution of ganglion cells in the retina of the fur seal Callorhinus ursinus. Brain, Behavior and Evolution, 39, 69-76.

Mass, A. M., \& Supin, A. Y. (2003). Retinal topography of the harp seal Pagophilus groenlandicus. Brain, Behavior and Evolution, 62, 212-222.

Mass, A. M., \& Supin, A. Y. (2005). Ganglion cell topography and retinal resolution of the Steller Sea lion (Eumetopias jubatus). Aquatic Mammals, 31, 393-402.

Melville, J., Schulte, J. A., \& Larson, A. (2001). A molecular phylogenetic study of ecological diversification in the Australian lizard genus Ctenophorus. Journal of Experimental Zoology, 291, 339-353.
Missotten, L. (1974). Estimation of the ratio of cones to neurons in the fovea of the human retina. Investigative Ophthalmology \& Visual Science, 13, 1045-1049.

Nagy, A., \& Ronald, K. (1970). The harp seal, Pagophilus groenlandicus (Erxleben, 1777). VI. Structure of retina. Canadian Journal of Zoology, 48, 367-370.

New, S. T., \& Bull, C. M. (2011). Retinal ganglion cell topography and visual acuity of the sleepy lizard (Tiliqua rugosa). Journal of Comparative Physiology A, 197, 703-709.

Nilsson, D.-E., \& Pelger, S. (1994). A pessimistic estimate of the time required for an eye to evolve. Proceedings of the Royal Society of London. Series B: Biological Sciences, 256, 53.

Ott, M. (2001). Chameleons have independent eye movements but synchronise both eyes during saccadic prey tracking. Experimental Brain Research, 139, 173-179.

Peichl, L. (1992). Topography of ganglion cells in the dog and wolf retina. Journal of Comparative Neurology, 324, 603-620.

Peichl, L. (2005). Diversity of mammalianphotoreceptor properties: adaptations to habitat and lifestyle? The Anatomical Record Part A: Discoveries in Molecular, Cellular, and Evolutionary Biology, 287, 1001-1012.

Perry, V., \& Cowey, A. (1988). The lengths of the fibres of Henle in the retina of macaque monkeys: Implications for vision. Neuroscience, 25, 225-236.

Peters, R. A., \& Evans, C. S. (2003). Introductory tail-flick of the Jacky dragon visual display: Signal efficacy depends upon duration. The Journal of Experimental Biology, 206, 4293.

Pettigrew, J., Dreher, B., Hopkins, C. S., McCall, M., \& Brown, M. (1988). Peak density and distribution of ganglion cells in the retinae of microchiropteran bats: Implications for visual acuity. Brain, Behavior and Evolution, 32, 39-56.

R Core Team. (2016). R: A language and environment for statistical computing. Vienna, Austria: R Foundation for Statistical Computing.

Ramos, J. A., \& Peters, R. A. (2015). Dragon wars: Movement-based signalling by Australian agamid lizards in relation to species ecology. Austral Ecology, 41, 302-315.

Reichenbach, A., \& Robinson, S. (1995). Phylogenetic constraints on retinal organisation and development. Progress in Retinal and Eye Research, 15, 139-171.

Röll, B. (2001a). Gecko vision-Retinal organization, foveae and implications for binocular vision. Vision Research, 41, 2043-2056.

Röll, B. (2001b). Retina of Bouton's skink (Reptilia, Scincidae): Visual cells, fovea, and ecological constraints. Journal of Comparative Neurology, 436, 487-496.

Schlesinger, C. A., Christian, K. A., James, C. D., \& Morton, S. R. (2011). Seven lizard species and a blind snake: Activity, body condition and growth of desert herpetofauna in relation to rainfall. Australian Journal of Zoology, 58, 273-283.

Schott, R. K., Müller, J., Yang, C. G., Bhattacharyya, N., Chan, N., Xu, M., ... Tropepe, V. (2016). Evolutionary transformation of rod photoreceptors in the all-cone retina of a diurnal garter snake. Proceedings of the National Academy of Sciences, 113, 356-361.

Shand, J., Chin, S. M., Harman, A. M., Moore, S., \& Collin, S. P. (2000). Variability in the location of the retinal ganglion cell area centralis is correlated with ontogenetic changes in feeding behavior in the black bream, Acanthopagrus butcheri (Sparidae, Teleostei). Brain, Behavior and Evolution, 55, 176-190.

Slomianka, L., \& West, M. J. (2005). Estimators of the precision of stereological estimates: An example based on the CA1 pyramidal cell layer of rats. Neuroscience, 136, 757-767.

Snyder, A. W., \& Miller, W. H. (1977). Photoreceptor diameter and spacing for highest resolving power. Journal of the Optical Society of America, 67, 696-698.

Stone, J. (1981). The whole mount handbook: A guide to the preparation and analysis of retinal whole mounts. Sydney, Australia: Maitland Publications.

Stone, J. (1983). Parallel processing in the visual system. New York, NY: Plenum Press. 
Teasdale, L., Stevens, M., \& Stuart-Fox, D. (2013). Discrete colour polymorphism in the tawny dragon lizard (Ctenophorusdecresii) and differences in signal conspicuousness among morphs. Journal of Evolutionary Biology, 26: 1035-1046.

Underwood, G. (1951). Reptilian retinas. Nature, 167, 183-185.

Walls, G. L. (1942). The vertebrate eye and its adaptive radiation. New York: Hafner.

Wässle, H. (2004). Parallel processing in the mammalian retina. Nature Reviews Neuroscience, 5, 747-757.

Wässle, H., Grünert, U., Röhrenbeck, J., \& Boycott, B. B. (1990). Retinal ganglion cell density and cortical magnification factor in the primate. Vision Research, 30, 1897-1911.

Wässle, H., Peichl, L., \& Boycott, B. (1981). Morphology and topography of on- and off-alpha cells in the cat retina. Proceedings of the Royal Society of London B: Biological Sciences, 212, 157-175.

Watt, M. J., \& Joss, J. M. P. (2003). Structure and function of visual displays produced by male jacky dragons, Amphibolurus muricatus, during social interactions. Brain, Behavior and Evolution, 61, 172-183.

West, M., Slomianka, L., \& Gundersen, H. J. G. (1991). Unbiased stereological estimation of the total number of neurons in the subdivisions of the rat hippocampus using the optical fractionator. The Anatomical Record, 231, 482-497.

Wilhelm, M., \& Straznicky, C. (1992). The topographic organization of the retinal ganglion cell layer of the lizard Ctenophorus nuchalis. Archives of Histology and Cytology, 55, 251-259.
Yewers, M. S., McLean, C. A., Moussalli, A., Stuart-Fox, D., Bennett, A. T. D., \& Knott, B. (2015). Spectral sensitivity of cone photoreceptors and opsin expression in two colour-divergent lineages of the lizard Ctenophorus decresii. Journal of Experimental Biology, 218, 1556-1563.

Zeil, J., \& Al-Mutairi, M. (1996). The variation of resolution and of ommatidial dimensions in the compound eyes of the fiddler crab Uca lactea annulipes (Ocypodidae, Brachyura, Decapoda). The Journal of Experimental Biology, 199, 1569-1577.

Zeil, J., \& Hemmi, J. M. (2006). The visual ecology of fiddler crabs. Journal of Comparative Physiology A, 192, 1-25.

\section{SUPPORTING INFORMATION}

Additional supporting information may be found online in the Supporting Information section at the end of this article.

How to cite this article: Nagloo N, Coimbra JP, Hoops D, Hart NS, Collin SP, Hemmi JM. Retinal topography and microhabitat diversity in a group of dragon lizards. $J$ Comp Neurol. 2020;528:542-558. https://doi.org/10.1002/cne. $\underline{24780}$ 